\title{
Public Health Workforce
}

\section{Future directions for the Bulletin}

\author{
D. Lynne Madden ${ }^{\mathrm{A}, \mathrm{C}}$, Megan E. Black ${ }^{\mathrm{A}}$, Carlie-Jane Naylor ${ }^{\mathrm{A}}$ and Richard Hecker \\ ${ }^{\mathrm{A}} N S W$ Public Health Bulletin, NSW Department of Health \\ ${ }^{\mathrm{B}}$ CSIRO PUBLISHING \\ ${ }^{\mathrm{C} C o r r e s p o n d i n g ~ a u t h o r . E m a i l: ~ l y n n e . m a d d e n @ d o h . h e a l t h . n s w . g o v . a u ~}$
}

We are very pleased to present with this issue a refreshed new look for the NSW Public Health Bulletin. This issue is also the first to be published through CSIRO PUBLISHING whose editorial and design team have worked with the Bulletin editorial team to develop this design, as well as the new website. These changes have been informed by surveys of the Bulletin readership, current practice in scientific journal publication and considerations of environmental sustainability.

New features for the publication include:

- An expanded table of contents that will appear as the back page of the issue. Each article title will be accompanied by a one-sentence description of the content.

- Contact details for the corresponding author and capacity for multiple affiliations for authors.

- Updated style of language to be aligned with current scientific usage.

The Bulletin has a new enhanced website located at http://www.publish.csiro.au/journals/phb. The NSW Health website will contain links to this site. There will be a transition period during which both the current Bulletin website and the new website will operate. The new production process will see the PDF and HTML versions of the Bulletin uploaded onto the new website in advance of the distribution of the printed copy.

The website has many new features:

- Readers can subscribe to an email notification system ('early alert') for new issues as they are uploaded to the Bulletin's website. The early alert provides readers with the contents of the issue and links to the articles.

- Reference lists cited by authors in the Bulletin will be linked to each cited paper if that paper is available on the Internet. This facility provides readers with immediate access to the evidence cited by authors.

- A 'most read' page to identify the most downloaded papers in the journal.

- A dedicated page for the special issues.

- An annual index of reviewers.

Several new resources have been developed and these are available through the website. For reviewers there is now a 'reviewer report form' that will provide a structure for reviewers to provide comments to both the editor and to the authors. This form is currently being piloted and we welcome feedback from reviewers who use it. For authors there are updated guidelines to publishing in the Bulletin. In coming weeks we hope to have a new resource that provides guidance on how to develop easy-to-read graphs and figures, based on the Better Health Graphs publication. ${ }^{1}$

Regarding sustainability, the Bulletin will be printed on archival quality chlorine-free paper using vegetable-based inks. The 'green' printer selected actively minimises waste through recycling all printing plates, offcut papers, and printing-related chemicals.

CSIRO PUBLISHING will manage the publication of the Bulletin - that is the production of the printed and electronic formats. The Bulletin editorial team assisted by a new Editorial Committee, remains responsible for the strategic direction, the management of the peer-review of articles, the selection of articles for publication, coordination of special issues and the content of the website.

Public health is a complex and evolving field and effective practice requires the integration and use of evidence. We would therefore like to encourage new and existing authors to continue to submit articles that describe their work to the 
Bulletin. We hope that the new production process will improve the Bulletin's timeliness, enable authors to reach a wider audience, give messages in the Bulletin greater penetration, and link readers to the broad public health literature. We look forward to receiving your comments about any of these new features.

\section{References}

1. Centre for Epidemiology and Research and Hunter Valley Research Foundation. Better Health Graphs (Volume 1): A report of an experimental study of interventions for improving graph comprehension. Sydney: NSW Department of Health, 2006.

\section{EDITORIAL}

\section{Strengthening learning opportunities to promote the capacity of the public health workforce}

\section{Lynne Madden}

Editor, NSW Public Health Bulletin.

Public Health Training and Development Branch, NSW Department of Health.

Email:lynne.madden@doh.health.nsw.gov.au

A skilled workforce is the major strategic resource for any industry. The articles in this issue propose ways to provide effective and accessible learning opportunities for the public health workforce in NSW and consider the potential contribution of standards to monitor population health practice including sustaining workforce capacity.

Problem solving skills in complex situations are particularly valued by health services and we need to develop this ability within the public health workforce. Research by Breen for the UK National Health Service found that effective workplace learning had three characteristics: it involved problem solving, occurred through group work and had the support of management. ${ }^{1}$ Problem-based learning (PBL) is well established in undergraduate and medical education, where it has been demonstrated to develop problem solving skills, critical thinking, teamwork and an ability to deal with complexity. Schmidt has shown that it helps medical students to acquire competencies relevant to professional practice. $^{2}$

Two articles 'Problem-based learning in public health workforce training: a discussion of educational principles and evidence' and 'Using problem-based learning in public health service based training' examine PBL methods and their potential application to workplace learning. Together these articles seek to answer whether PBL can be applied in postgraduate public health education that is delivered within the service environment.
Trevena reviews the literature describing the use of PBL in health education, and public health education in particular. Despite the benefits and growing application of PBL in health education there is a scarcity of literature describing its application in public health, particularly at the postgraduate level. This paper was used to inform discussions to develop a PBL approach for the NSW Public Health Officer Training Program. Heading, Lyle, Fuller and Madden describe an outcome of these discussions, a PBL workshop developed by The Broken Hill University Department of Rural Health in partnership with public health professionals from the Greater Western Area Health Service and the Training Program. The evaluation of this workshop found that participants like this way of working and learning. These findings were applied to a second PBL workshop for the Training Program, developed by the Northern Rivers University Department of Rural Health and public health professionals from the North Coast Area Health Service.

There is a growing appreciation of the potential contribution that telehealth can make to education, training, mentoring and administrative functions for public health. The use of communication technologies offers one way to increase equity of access to learning opportunities between locations and in particular for isolated practitioners in rural and remote settings. Twenty-six percent of the NSW population live in rural and remote areas and these populations generally have lower health status than the rest of NSW. The NSW Telehealth Initiative was established in 1996 to improve access to health services for these people. Since then it has sought to both expand existing services and encourage innovation in the application of the technologies to support the health of the people of NSW. The NSW Telehealth Initiative is now one of the largest 
integrated telehealth networks in the world with 270 sites across NSW.

However, the capacity of the public health workforce to engage with these resources has been restricted by their knowledge of communication technology and how and when the different techniques are best applied. The article 'Use of communication technologies by the public health workforce in NSW' describes the findings of a study undertaken in partnership with the NSW Telehealth Initiative. This survey of a small sample of public health workers explored their current understanding and use of communication technology for both training and general communication purposes. Resources like the Bug Breakfast Delivery Manual (a brief description of which follows the telecommunications article) are designed to help the workforce use communication technologies efficiently.

Two of the standards included in the recently developed Population Health Standards for Area Health Services are that there is an appropriate workforce to undertake population health activities and that the area health service has training and support systems in place to optimise and retain its workforce. The article 'Influencing population health performance: introduction of standards for area health services in New South Wales' describes the development of these standards by the NSW Department of Health and the subsequent piloting of these standards in the Greater Western Area Health Service. These standards are seen as a way to improve organisational performance in population health and complement the development of similar standards at a national level and by other countries. ${ }^{3}$
The medical teams from Australia that responded to the tsunami that occurred on Boxing Day 2004 included many public health professionals. The final article in this issue 'Health surveillance among Australian health workers assisting tsunami victims in Aceh, Indonesia' describes the measures taken to protect the health of the first medical team that went to Aceh in Indonesia following the tsunami. This article offers suggestions for how to prevent illness among a workforce located in a difficult environment.

Since 1990 when systematic public health structures in NSW were considerably augmented, NSW Health has continued to develop a public health infrastructure and workforce. Growing the capacity of this public health workforce, helping them to acquire knowledge and skills to meet both existing and emerging workplace issues while also recognising their passion and commitment, is a challenge. The articles in this issue offer innovative ways to achieve this.

\section{References}

1. Breen R. Workplace learning and the National Health Service University. In Workman B (ed.), Work based learning: Innovations and Applications. London: Kingsham Press, 2005.

2. Schmidt $\mathrm{H}$. Changing perspectives on problem-based learning. Symposium proceedings, Re-inventing $P B L$. International Problem-Based Learning Symposium; February 2007; Singapore.

3. National Public Health Partnership (NPHP) Public Health Classifications Project Phase One: Final Report. Melbourne: NPHP, 2006. 


\section{Problem-based learning in public health workforce training: a discussion of educational principles and evidence}

\author{
Lyndal J. Trevena \\ School of Public Health, The University of Sydney. \\ Email:lyndalt@health.usyd.edu.au
}

\begin{abstract}
Problem-based learning (PBL) has been implemented within numerous undergraduate health curricula but less so in workforce training. Public health practice requires many of the skills that PBL aims to develop such as teamwork, selfdirected learning and the integration of multiple sources of information within problem solving. This paper summarises the historical development of PBL and the educational principles underpinning it. It hypothesises that the public health workforce would benefit from some exposure to this type of learning and highlights some of the practical issues for its implementation.
\end{abstract}

Problem-based learning (PBL) was originally developed by Barrows and Tamblyn at McMaster University, Canada, to help medical students integrate knowledge across subject boundaries and develop problem-solving skills during their neurology training. ${ }^{1}$ PBL was educationally innovative because it allowed students to blend new knowledge acquired from external sources with their existing knowledge-base, and apply it. This paper provides a targeted review of the literature and a discussion of the development and use of PBL in health education. It raises questions about the potential application of PBL in public health workforce training.

\section{Defining PBL}

Other educational methods that bear a superficial resemblance to PBL, such as 'discovery learning', rely on students sharing their knowledge with each other but not obtaining it from external sources. PBL also differs from a 'case study approach', which tends to get students to solve problems after gaining some knowledge. Despite its rapid adoption over the last decade, particularly within medical curricula, there is still some confusion over what PBL means. $^{2}$
The distinguishing feature of PBL is that it begins with a problem and is followed by a student-centred enquiry process. There are no specific readings or lectures before students are presented with the problem. However, students bring previously acquired knowledge from a range of sources to what is usually a group of approximately eight randomly assigned learners and a tutor-facilitator. Students work collaboratively to define the problem, formulate enquiry plans and identify external sources for solving the problem. They also work together to analyse information and apply it. In medical education the problem often has a simulated or virtual patient, and uses a video or sometimes computer images of patient signs, symptoms, pathology and radiology results to mimic professional practice. The PBL process usually occurs over several tutorials within a week, allowing time for information to be gathered from external sources and brought back to the group process.

\section{Educational principles underpinning PBL}

Barrows defined four broad goals for PBL: ${ }^{3}$

(1) Motivational learning

(2) Developing effective clinical reasoning

(3) Developing self-learning skills

(4) Structuring knowledge in clinical contexts.

These goals were subsequently expanded by Schmidt, ${ }^{4}$ who defined seven steps to the PBL process (Box 1). Many variations to, and newer versions of, PBL have been developed since Barrows' work in the 1970s and Schmidt's in the 1980s, but most educators would probably agree that the principles above are the foundation on which PBL is built.

Box 1. Seven steps in problem-based learning.

1. Clarify terms and concepts not readily comprehensible

2. Define the problem

3. Analyse the problem

4. Draw a systematic inventory of the explanation inferred from step 3

5. Formulate learning objectives

6. Collect additional information outside the group

7. Synthesise and test the newly acquired information

Source: Schmidt H. Problem-based learning: Problem and definition. Medical Education 1983. ${ }^{4}$ 


\section{Matching educational methods with learning needs}

Many believe that PBL incorporates the principles of adult learning better than other modalities by encouraging the development of skills that prepare students for selfdirected life-long learning rather than the recall of facts that quickly go out-of-date. ${ }^{2,5}$ The PBL process therefore requires some cognitive skills of a high order.

Almost 50 years ago, Benjamin Bloom proposed a taxonomy of educational goals, with two domains, 'affective' and 'cognitive', comprising educational objectives of increasing complexity. ${ }^{6}$ In the affective domain, learning moves from receiving (e.g. attendance) through responding, valuing, organisation and finally characterisation. Thus, the affective domain becomes increasingly integrated within the learners' behaviour. In the cognitive domain, goals are achieved in both knowledge and skills. Knowledge attainment begins with facts and terminology, and considers trends, sequences, classifications, methodologies and finally principles and theories. Knowledge is then applied as an intellectual ability or skill via comprehension (i.e. translation, interpretation and extrapolation), application, analysis (of elements, of relationships and of organisational principles), synthesis (through unique communication, production of a plan or proposed set of operations, and derivation of abstract relations) and evaluation (judgements in terms of internal evidence and of external criteria). Clearly, PBL aims to achieve educational goals at both the high end of the affective domain and in knowledge and skills acquisition.

While the use of the word 'problem' implies that something needs 'fixing', within the learning context it can involve students being presented with a set of unfamiliar circumstances. In a PBL task, the students would be required not only to recognise patterns within the problem but also to obtain and apply knowledge in a logical and analytical way to solve the problem. ${ }^{7}$
Implementing the PBL method within a curriculum In addition to confusion about the nomenclature of PBL, there is confusion about its implementation within curricula. The PBL label has, according to some, been subverted and used in problem-oriented curricula. ${ }^{8}$ Ross maintains that the distinguishing characteristic of PBL is that knowledge arises from working on the problem rather than being a prerequisite for working on the problem. ${ }^{8}$ This is often an iterative process and usually self-directed, where learning occurs without the constraints of subject boundaries.

At what point then should students be exposed to PBL? Are they able to utilise this framework early in their learning or do they need to work towards it in some way? PBL has been used within undergraduate, graduate and continuing education environments but it is unclear whether it is equally effective at all three stages of learning. Barrows himself suggested that medical students might need to work towards PBL through a taxonomy of learning methods (Box 2). Only the final two truly provide a framework for achieving Barrows' four goals of PBL. Some PBL curricula use only these final two learning formats, while others allow students to work towards these by using case-based methods in the earlier part of their course. The most effective approach remains unclear.

\section{Evidence for the effectiveness of PBL}

The effectiveness of PBL as a learning method has been the source of much debate in the literature. 5,9 Three systematic reviews ${ }^{10-12}$ were conducted in the early 1990 s comparing PBL with traditional medical curricula, and these found some evidence (from students' opinions and attitudes to programs) that PBL graduates had a more positive learning experience, performed at least as well in clinical examinations and were more likely to enter family medicine than other graduates. There was also some evidence that basic science scores were lower in PBL graduates than in their traditionally taught counterparts. These systematic reviews were updated by Colliver in $2000,{ }^{9}$

Box 2. Barrows' taxonomy of problem-based learning.

- Lecture-based cases: cases used to demonstrate the relevance of information provided by lecture

- Case-based lectures: cases are used to highlight material to be covered in the subsequent lecture

- Case method: cases are studied in preparation for class discussion

- Modified case-based method: cases provide opportunities for deciding between a limited number of options

- Problem-based learning: cases are used in a problem simulation format encouraging free inquiry

- Closed loop, or reiterative, problem-based learning: a reflective phase complements the problem-based format

Source: Barrows $\mathrm{H}$. A taxonomy of problem-based learning methods. Medical Education 1986. ${ }^{3}$ 
who claimed that improvements in knowledge and clinical performance attributable to PBL were not great enough to be practically significant. This has been refuted by Blake et al., who published an analysis of United States Medical Licensing Examination results of four PBL classes compared with two traditional classes graduating from University of Missouri-Columbia School of Medicine. ${ }^{13}$ They showed that students from the PBL curricula had higher mean scores in the Step 1 examination (basic sciences) than those in the traditional curriculum. The PBL students also had scores higher than the national mean in the Step 2 examination (clinical sciences), unlike students in the traditional curriculum whose mean score was lower than the national mean. Both groups had similar selection characteristics and processes and Blake infers that the PBL learning process substantially contributed to this improved educational outcome.

Dean et al. ${ }^{14}$ compared the performance of NSW hospital interns who completed graduate entry PBL courses with that of interns who completed undergraduate PBL and traditional undergraduate courses in 2003. The analysis showed that graduate entry PBL interns felt more prepared in five of the eight assessed domains (interpersonal skills, confidence, collaboration, holistic care and self-directed learning) and felt no less prepared in any domain than the interns from the other courses. ${ }^{14}$

A systematic review of controlled evaluation studies in problem-based continuing medical education found limited evidence that it increased participants' knowledge and performance and improved patients' health. There was moderate evidence that doctors were more satisfied with PBL compared with traditional teaching approaches. ${ }^{15}$ Similar results have also been found in the evaluation of PBL methods within nursing, dentistry, pharmacy, anatomy, pharmacology and allied health curricula. ${ }^{16-20}$

In summary, there is evidence from medical and other health undergraduate curricula, as well as continuing medical education, that PBL graduates achieve equivalent, if not better, scores in knowledge-based assessments (mainly multiple choice question and short answer) and clinical examinations than their traditional counterparts. In addition to this, PBL curricula generally receive a higher satisfaction rating from students.

\section{Limitations of the evidence}

Revisiting Barrows' goals, PBL should produce graduates who are motivated, self-directed learners, who are able to develop effective reasoning strategies and structure knowledge effectively within the context to which it is applied. However, multiple choice questions, short answer questions, clinical examinations and satisfaction measures fall short of assessing whether these goals are achieved. The higher up Bloom's taxonomy one goes, the more dif- ficult it is to assess the educational outcomes. It is likely that workplace assessments, performance and evaluations across a range of outcomes are more appropriate. These could assess attitudes and skills as well as knowledge, thereby considering whether values such as interdisciplinary teamwork and skills in self-directed problem solving have been attained. There is a need for more research in this area.

A related issue to outcome measurement is the lack of available data on the cost-effectiveness of PBL curricula. This remains a substantive issue, as PBL is potentially resource-intensive, requiring skilled tutor-facilitators, high quality learning resources for self-directed problem solving and greater timetable allocation for small group work and associated facilities.

\section{PBL in public health education}

Public health practice involves considerable problem solving. It usually involves working within groups and with numerous stakeholders. And according to Bloom's taxonomy, it requires analytical and organisational skills of the highest order. The public health workforce comprises mainly tertiary-trained adult learners who are required to be self-directed and highly motivated in their work. They need to be able to obtain and synthesise information from external sources and to apply this to the problems, projects or circumstances before them.

Yet, the use of PBL in public health is largely uncharted territory. Several examples of case-based but not problembased learning in public health undergraduate and postgraduate courses exist, but they have not been formally evaluated, particularly in workforce training contexts. ${ }^{21-23}$ Some reports also exist on the integration of public health learning objectives within problem-based medical undergraduate curricula, but not on the use of this educational method to solve problems at a population level. ${ }^{24,25}$ The one exception to this is an innovative series of PBLs developed in Hong Kong, covering such topics as air pollution, tobacco control and mammography screening. ${ }^{26}$

What would one hope to achieve through problem-based public health workforce training? Would it result in higher levels of motivation, greater application of knowledge in the workplace, better teamwork and a more self-directed workforce? The NSW Public Health Officer Training Program may be one place to begin testing these ideas because it provides a structured and stable learning environment for a small number of trainees. There would be considerable educational challenges in developing a PBL approach to population rather than individual patient problem solving. Public health problems often have more than one solution; they are often extremely complex and may need to be broken down into several problems within a 'meta-problem'. As discussed earlier, there are also 
ongoing challenges in the assessment of competence in PBL learning outcomes that would need to be defined specifically for the public health context. Regardless of the clinical derivation of PBL, its educational principles nevertheless resonate with public health problem solving in practice.

\section{Implementing PBL in public health education}

The geographical dispersion of the public health workforce and competing workplace demands add a layer of complexity that does not exist for campus or hospitalbased medical undergraduate curricula. Most PBL curricula are conducted through small groups that remain stable for several problems, allowing for the development of team-working skills. When considering how PBL might be implemented in public health workforce training, it is important to consider public health team composition.

The delivery of PBL methods by distance learning is an emerging area. ${ }^{27,28}$ Teleconferencing and videoconferencing have been used with undergraduate nurses and in continuing medical education. While these modalities improve access to remote learners, there are numerous factors that can reduce the quality of learning. Limited reports on teleconferencing show a high time-demand on tutor-facilitators and difficulties in group facilitation due to a lack of visual cues. ${ }^{29}$ Although videoconferencing provides the visual dimension, it is costly and still requires a particular etiquette and considerable skill to ensure participation across several sites. ${ }^{30}$ Others have tried webbased asynchronous discussions within small online groups. While this method lacks the spontaneity of 'live' discussion, it has the benefit that people can participate at a time that suits their own working environment and other commitments. Responses can also be more reflective. ${ }^{31,32}$

Despite these challenges, the potential exists for substantial educational gains in a field that is, as yet, largely unexplored. In theory, the fundamental educational principles of PBL should be relevant to the learning needs of the NSW public health workforce. Translating the PBL framework to population level problem solving, defining the outcomes of the PBL process, measuring them and determining the most appropriate method of delivery will be crucial to the success of such a project. Pilot testing of this learning method within the NSW Public Health Officer Training Program and subsequent testing with more experienced NSW public health practitioners undertaking continuing education might begin to provide some answers to these questions.

\section{Acknowledgement}

This paper was commissioned by the NSW Department of Health.

\section{References}

1. Neufeld V, Barrows H. 'The McMaster philosophy': an approach to medical education. J Med Educ 1974; 49(11): 1040-50.

2. Maudsley G. Do we all mean the same thing by 'problembased learning'? A review of the concepts and a formulation of the ground rules. Acad Med 1999; 74(2): 178-85.

3. Barrows H. A taxonomy of problem-based learning methods. Med Educ 1986; 20: 481-6.

4. Schmidt H. Problem-based learning: problem and definition. Med Educ 1983; 17: 11-6.

5. Albanese M. Problem-based learning: why curricula are likely to show little effect on knowledge and clinical skills. Med Educ 2000; 34: 729-38. doi:10.1046/j.13652923.2000.00753.x

6. Bloom B, editor. Taxonomy of educational objectives: the classification of educational goals, by a committee of college and university examiners. Handbook I, Cognitive domain. New York: David McKay, 1956.

7. Walton H, Matthews M. Essentials of problem-based learning. Med Educ 1989; 23: 542-58.

8. Ross B. Towards a framework for problem-based curricula. In: Boud D, Feletti G, editors. The challenge of problem-based learning. London: Kogan Page, 1991.

9. Colliver J. Effectiveness of problem-based learning curricula: research and theory. Acad Med 2000; 75(3): 259-66. doi:10.1097/00001888-200003000-00017

10. Albanese M, Mitchell S. Problem-based learning: a review of literature on its outcomes and implementation issues. Acad Med 1993; 68: 52-81. doi:10.1097/00001888-19930100000012

11. Vernon D, Blake R. Does problem-based learning work? A meta-analysis of evaluative research. Acad Med 1993; 68: 550-63. doi:10.1097/00001888-199307000-00015

12. Berkson L. Problem-based learning: have the expectations been met? Acad Med 1993; 68(Suppl.): S79-88. doi:10.1097/00001888-199310000-00053

13. Blake R, Hosakowa M, Riley S. Student performances on Step 1 and Step 2 of the United States Medical Licensing Examination following implementation of a problem-based learning curriculum. Acad Med 2000; 75(1): 66-70. doi:10.1097/00001888-200001000-00017

14. Dean S, Barratt A, Hendry G, Lyon P. Preparedness for hospital practice among graduates of a problem-based, graduate-entry medical program. Med J Aust 2003; 178(4): $147-8$.

15. Smits P, Verbeek J, de Buisonje C. Problem-based learning in continuing medical education: a review of controlled evaluation studies. BMJ 2002; 324: 153-6. doi:10.1136/bmj.324.7330.153

16. Reynolds F. Initial experiences of interprofessional problembased learning: a comparison of male and female students' views. J Interprof Care 2003; 17(1): 35-44. doi:10.1080/1356182021000044148

17. Prince K, van Mameron H, Hylkema N, Drukker J, Shcherpbier A, van der Vleutin C. Does problem-based learning lead to deficiencies in basic science knowledge? An empirical case on anatomy. Med Educ 2003; 37: 15-21. doi:10.1046/j.1365-2923.2003.01402.x 
18. Pang S, Wong T, Dorcas A, Lai C, Lee R, Lee W et al. Evaluating the use of developmental action inquiry in constructing a problem-based learning curriculum for preregistration nursing education in Hong Kong: A student perspective. $J A d v$ Nurs 2002; 40(2): 230-41. doi:10.1046/j.1365-2648.2002.02365.x

19. International Problem-Based Learning Network Use of problem-based learning in Canadian and US dental schools: results of a survey. J Can Dent Assoc 2002; 68(1): 26.

20. Antepohl W, Herzig S. Problem-based learning versus lecturebased learning in a course of basic pharmacology: a controlled, randomized study. Med Educ 1999; 33(2): 106-13. doi:10.1046/j.1365-2923.1999.00289.x

21. Pearson T, Barker W, Fisher S, Trafton S. Integration of the case-based series in population-oriented prevention into a problem-based medical curriculum. Am J Prev Med 2003; 24(4): 102-7. doi:10.1016/S0749-3797(03)00030-8

22. Wiers R, van der Wiel M, Sa H, Mamede S, Tomaz J, Schmidt H. Design of a problem-based curriculum: a general approach and a case study in the domain of public health. Med Teach 2002; 24(1): 45-51. doi:10.1080/00034980120103478

23. Petersen D, Ginter P, Hovinga M, Williams O, Jacobs R, Davies S. Public health case studies: a new MPH requirement bridging academia and practice. $J$ Public Health Manag Pract 2001; 7(3): 86-91.

24. Trevena L, Clarke R. Self-directed learning in population health. A clinically relevant approach for medical students. Am J Prev Med 2002; 22(1): 59-65. doi:10.1016/S07493797(01)00395-6
25. Stone D. Public health in the undergraduate medical curriculum - can we achieve integration? J Eval Clin Pract 2000; 6(1): 9-14. doi:10.1046/j.1365-2753.2000.00227.x

26. Leung G, Lam T, Hedley A. Reports of new ideas in medical education: problem-based public health learning - from the classroom to the community. Med Educ 2001; 35: 1066-90. doi:10.1046/j.1365-2923.2001.1077a.x

27. Price B. Problem-based learning the distance learning way: a bridge too far? Nurse Educ Today 2000; 20: 98-105. doi:10.1054/nedt.1999.0379

28. Edwards N, Hugo K, Cragg B, Peterson J. The integration of problem-based learning strategies in distance education. Nurse Educ 1999; 24(1): 36-41. doi:10.1097/00006223-19990100000011

29. Choi H. A problem-based learning trial on the Internet involving undergraduate nursing students. J Nurs Educ 2003; 42(8): 359-63.

30. Allen M, Sargeant J, Mann K, Fleming M, Premi J. Videoconferencing for practice-based small-group continuing medical education: feasibility, acceptability, effectiveness and cost. J Contin Educ Health Prof 2003; 23(1): 38-47. doi:10.1002/chp.1340230107

31. Salmon G. E-moderating: the key to teaching and learning online. London: Kogan Page, 2000.

32. Elwyn G, Greenhalgh T, MacFarlane F. Groups: a guide to small group work in healthcare, education and research. Oxford: Radcliffe Medical Press, 2001.

\section{Bug Breakfast Delivery Manual available on the NSW Health Intranet}

The Bug Breakfast Delivery Manual has been developed as a resource to assist the delivery of professional development activities by videoconference.

The Public Health Training and Development Branch and Communicable Diseases Branch of the NSW Department of Health coordinate the delivery of Bug Breakfast (a series of hour-long breakfast seminars on communicable diseases that are held monthly). The seminars are delivered to an on-site audience at the Department of Health in North Sydney and are broadcast via videoconference to 19 remote sites across NSW.

To support the regular delivery of Bug Breakfast, the Public Health Training and Development Branch has developed a Bug Breakfast Delivery Manual. The Manual provides a complete description of the procedures to be followed and resources required to deliver a live training session to multiple remote sites via videoconference.

Other groups that use videoconferencing to deliver professional development activities may find the Manual a useful resource. The Manual will be updated annually and is available to be downloaded from the Bug Breakfast web pages on the NSW Health Intranet site.

The Bug Breakfast web pages can be accessed from the NSW Health Intranet site at the following web address: http://internal.health.nsw.gov.au/public-health/bugbreakfast/index.html.

For further information about Bug Breakfast or the Bug Breakfast Delivery Manual, contact the Bug Breakfast Coordinator, Public Health Training and Development Branch, NSW Department of Health by email at BugBreakfast@doh.health.nsw.gov.au. 


\section{Using problem-based learning in public health service based training}

\author{
Gaynor S. Heading ${ }^{\mathrm{A}}$, Jeffrey D. Fuller ${ }^{\mathrm{B}, \mathrm{D}}$, \\ David M. Lyle ${ }^{\mathrm{A}}$ and D. Lynne Madden ${ }^{\mathrm{C}}$ \\ ${ }^{\mathrm{A} B r o k e n ~ H i l l ~ C e n t r e ~ f o r ~ R e m o t e ~ H e a l t h ~ R e s e a r c h, ~ B r o k e n ~ H i l l ~}$ \\ University Department of Rural Health, University of Sydney \\ ${ }^{\mathrm{B} N o r t h e r n ~ R i v e r s ~ U n i v e r s i t y ~ D e p a r t m e n t ~ o f ~ R u r a l ~ H e a l t h, ~}$ \\ University of Sydney and Southern Cross University \\ ${ }^{\mathrm{C}}$ Public Health Training and Development Branch, NSW \\ Department of Health \\ DCorresponding author.Email: jeffreyfuller@nrahs.nsw.gov.au
}

\begin{abstract}
Objectives: This study explored the suitability and benefits of problem-based learning (PBL) in competency-based postgraduate public health training. The PBL was delivered within a rural retreat and included site visits. Methods: Qualitative semistructured interviews with trainee public health officers and key informants. Results: The learning approach (retreat-PBL combination with site visits) was valuable and relevant. Trainees reported a high learning impact with increased knowledge about the problems examined and rural public health practice. They also expressed an openness to work rurally. Conclusion: Collaboratively developed and delivered, experiential rural public health PBL provides a positive learning experience for trainees undertaking competency-based training in public health and could play an important workforce role. PBL appears to be suitable in rural and non-rural public health training settings.
\end{abstract}

Problem-based learning (PBL) is valued in undergraduate health science curricula as a means of developing critical thinking, problem-solving skills, teamwork skills and the ability to deal with complexity ${ }^{1}$ - all attributes considered important for public health practice. The distinguishing features of PBL include active self-directed learning where small tutor-facilitated groups encounter a problem and then seek solutions, with no advanced readings or lectures. ${ }^{2}$ The method involves learners exploring their preexisting knowledge and seeking additional information to advance their understanding. ${ }^{2}$ Active participation leads to more satisfying learning ${ }^{3}$ and greater knowledge and clinical reasoning skills. ${ }^{4}$ PBL has focused mainly on clinical situations; however, population problems can effectively be used when they use 'progressive disclosure', reflect 'real-life situations', and have a broad title that directs thinking to population issues. ${ }^{5}$ While the inclusion of PBL in undergraduate public health education appears sound, ${ }^{6}$ its suitability has largely been ignored in professional training. ${ }^{7}$

During November 2005, nine trainees, seven in their final year of the NSW Public Health Officer Training Program (the Program), who had completed a 6-month rural rotation, and two from linked programs, participated in a week-long rural training retreat that incorporated PBL. The retreat was held in Broken Hill, a small city in arid Australia located $1200 \mathrm{~km}$ west of Sydney (where the Program is based). The retreat included active learning about the communities located along the rail corridor that trainees travelled through during a 12-hour train trip from Sydney to Broken Hill; a 4-day PBL on water quality (a major public health issue in Broken Hill); site visits; and meetings with public health professionals. The PBL involved three facilitated sessions over 4 days. The first session focused on the scenario, problem identification, information gathering and problem reformulation; the second session considered options for solving the problem; and the third session addressed emerging issues and discussion points.

The development of a public health PBL scenario for the Program was the initiative of the NSW Department of Health and arose from an interest in exploring new ways in which to deliver service-based training. The Broken Hill University Department of Rural Health was contracted to develop the PBL scenario, and this was accomplished in consultation with key stakeholders, including staff from the Program.

The study explored the benefits that exist for trainee public health officers who undertake rural training within a retreat that incorporates a public health PBL exercise and how well this fits with the delivery of a competency-based postgraduate training program. The impact and desirability of new ways of delivering public health training through active on-site learning about rural public health issues and communities involving PBL and site visits (including the train journey) were examined. 


\section{Methods}

Data collection for the evaluation of the training package was by qualitative means. Semistructured in-depth interviews averaging 30 minutes in duration were undertaken with 19 respondents (all nine trainees and 10 key informants). Key informants were staff involved in the retreat planning or PBL delivery from the Program, Greater Western Area Health Service Population Health Unit and two university departments of rural health. They were invited to participate in the evaluation by two of the authors (GH or JF). Two potential key informants were not available at the time of interview. Interviewing commenced the week after the training finished and took about 3 weeks. All respondents gave informed consent. Interviews were taperecorded, with notes typed into a word-processor file. Data were separately coded (by GH and JF) with cross-coder verification. There was high agreement between coders. A few minor differences in interpretation were discussed and agreement was reached about a thematic framework. The evaluation explored the: (a) value of a PBL approach within a training retreat; (b) learning impact; and (c) factors to explain the effectiveness of this means of delivery. The results section presents the findings for the first two points while the value of retreat-style training that incorporates $\mathrm{PBL}$ is explored in the discussion section.

\section{Results}

Trainees (three male and six female) liked the practical focus of the retreat and the PBL, and also the hospitality they received in Broken Hill. The key informants involved in the development of the PBL and its delivery wanted to know if it would work, and were pleased with the trainees' engagement with the exercise. The local public health unit staff were satisfied with their involvement, as the exercise allowed them to reflect on their work and to see the problem examined in a broader context (Box 1, quotes $1-2)$.

\section{The learning approach}

While experiential learning was the most valuable aspect of the retreat, there were a few minor problems such as the 3-hour delay in the departure of the train from Sydney. While the delay added frustration to a long trip, the journey was designed as a learning opportunity, introduc-

\section{Box 1. Satisfaction (quotes 1-2)}

1. In hindsight it feels that it worked better than a lot of other training that is theoretical and removed from the real world. There should be more of it. (Trainee 6)

2. I think it is a good opportunity for people to sit back and look at what they do ... and take some method to pull it all together ... There is a tendency to be a bit on our own out here and so it is good to bring them [public health unit staff] into a bigger network and have them exposed to a group of [public health officer trainees] and to think about different ways to approach problems. (Key Informant 3) ing trainees to rural issues including the realities of travelling to remote locations (Box 2, quote 3).

There was unanimous support for the use of a PBL exercise and learning in situ. The benefit of studying remote public health issues through a PBL exercise in a rural location was recognised as having an impact bigger than being in [the city]'. Trainees were happy with the pace of learning and length of the training and valued having access to experts, local professionals, site visits and written resources. More than half of the trainees commented on the resources and how the PBL was supported by 'easy access to information' and 'experts', which allowed 'clarity and guidance'. A few thought that it would have been better if they had to undertake more of a 'mental hunt down' for appropriate resources; however, others noted that easy access to resources was beneficial given that only 4 days were available for the PBL.

Trainees enjoyed the engaging nature of the PBL. The retreat-PBL combination created a 'variety of learning experiences' and trainees appreciated how the PBL topic had 'complexity that unfolded gradually'. According to the trainees, this made the training realistic, relevant, practical and 'learner centred' (Table 2, quotes 4-6). There was some criticism, however, when a site visit was not linked well to the PBL and did not capitalise on an expected learning opportunity. This experience illustrated the effort required to maximise the learning potential from site visits.

The focus on one public health issue in one location did limit trainees' exposure to a broad range of rural and remote public health issues and about half of the trainees expressed the desire to have explored additional environ-

\section{Box 2. Experiential learning (quotes 3-6)}

3. [It was] important that at least one trip was made by train to impart ... the concept of distance ... and what isolation might mean. [The three hour] train malfunction may have been negative for a few Trainees, but this was very realistic, as people travelling to remote locations do not have many travel choices and if the train is late and there is no plane to quickly jump on ... you have no choice under such circumstances. (Key Informant 18)

4. It would be hard to imagine what a town would be like. (Trainee 1)

5. Site visits helped to increase understanding because I could see things, which helps to put these things into a practice context. It was good to see ... the lake system and what we are talking about to put that back into our discussion in our small groups. This was about a public health problem. It was and kept unfolding and changing and continued to evolve as we got into it. (Trainee 2)

6. The training was not too pressured so you could immerse yourself in the environment and absorb things rather than just the textbook experiences. (Trainee 4) 
mental health and Aboriginal health issues. Other trainees, however, reported that dealing with one problem enabled them to gain a deeper understanding of the principles of public health practice. Moreover, additional content would have limited their immersion in the historical, cultural and social context in which the problem arose. As public health strategies are implemented within and influenced by local context, experiencing this is a relevant and important aspect of learning.

\section{Learning impact}

The perceived relevance of PBL to public health training was in the development of problem solving and teamwork competencies in a simulated real world context (Box 3, quotes 7-9). While trainees reported increased knowledge about water quality, the more profound and surprising impact for them was to see the mutually supportive form of public health practice that has developed in Broken Hill.

\section{Box 3. Learning impact (quotes 7-14)}

7. The PBL approach is as close to real as you can get. The students had to work as a team and get resources and to then think about the consequences of their decisions. (Key Informant 6)

8. [In] most of the training ... we bring in experts ... around single competency areas. That doesn't really reflect what these guys do on the job, most of the time they are usually working around several competency areas at any one time. (Key Informant 12)

9. You have to go through the analytic process that would be encountered in real practice. (Trainee 4)

10. The unique aspect was the extent to which those in the local community support each other. I expected that I would find people working in stand-alone situations and relying on accessing public health specialist expertise in Sydney. I expected I would find more of them working in professional isolation. (Trainee 2)

11. I have an increased understanding of the nuances, that is, that the negative aspects, such as isolation, also have positive aspects, such as leading to closer working relationships. (Trainee 4)

12. I'm open to Broken Hill but can't generalise. It doesn't mean I'm open to all rural. A rotating position (secondment) as part of a program would be good ... The type of work will influence. A six to twelve-month's secondment would be good. (Trainee 1)

13. While my views have not changed regarding the issues of distance and isolation, I did see the support structures that are available in Broken Hill, particularly how there are close partnerships between professionals that collectively increase their resources ... [and] technology such as videoconference that reduces isolation. (Trainee 2)

14. When in a new environment [I] will get out and drive around and take photos, not just sit and look at the map. Get out and see for myself. It has always worried me how [some practitioners] never visit to see how things work. The PBL reinforced that we can all be a bit lazy. Actually meeting people really reinforced that need. (Trainee 5)
While this has been born of necessity due to distance from other public health specialists, it has been actively cultivated by local practitioners (Box 3, Quotes 10-11). The awareness that distance did not mean absolute professional isolation appeared to open a few trainees to the possibility of future remote public health work (Box 3, quotes 12-13).

While the impact of PBL in a 1-week retreat may be limited, one trainee made the point that the impact was amplified by the magnitude of the difference between urban Sydney and Broken Hill. The impact of training held in less-isolated rural settings is worth exploring. Another trainee noted the importance of undertaking site visits to develop a sound understanding of a location and the related issues. They reported how the retreat-PBL had confirmed for them the value of undertaking site visits and how they would build these into future work practice (Box 3, quote 14).

\section{Discussion}

The retreat-PBL approach appears to be constructive and is aligned with the aims of the Program, which is to produce graduates who are competent to work strategically with other public health practitioners to resolve public health issues in NSW. This learning approach also requires the simultaneous application of many of the competency areas from the competency framework on which the Program is based. ${ }^{8}$ Further, it augments the learning that trainees gain during the 6-month rural work experience that they are required to undertake.

The learning principles underpinning the PBL are aligned with contemporary learning theory (e.g. constructive, selfdirected, collaborative and contextual learning). ${ }^{9}$ Although electronic and class room learning may eliminate the need for rural visits, the results suggest that the efficacy of the PBL was directly linked to the experiential and contextual aspects derived from the rural visit, which led to increased knowledge and greater understanding and insight (e.g. into practical solutions to isolated practice). These same positive outcomes may not be present if trainees study a rural public health topic from an urban location. In addition, site visits can avoid some of the weaknesses related to distance learning such as content inflexibility ${ }^{10}$ and are an important part of a problem assessment.

The location, structure and suitability of the problems used to develop a rural PBL need consideration. In this case, the PBL within a retreat worked. The effectiveness of this experience may be related in part to the remote location of its delivery, which was very different from the trainees' usual experience and so captured their interest. A less isolated rural retreat may not have the same impact.

Other crucial ingredients for effectiveness appear to be collaboration between the NSW Public Health Officer 
Training Program, public health academics and public health practitioners at the planning and delivery stages. In this case, the lead academic involved with the development and delivery had a public health background, was familiar with the Program and had good relationships in Broken Hill. The PBL designers knew what a public health PBL should contain and how it should unfold. The PBL kept the interest of the trainees as it covered the technical, human and political aspects of the problem. Collaboration made the PBL real, with a variety of expertise contributing to the learning, the problem and the context. Despite the constructive planning process based on transparency and trust and the associated positive learning environment, additional stakeholder involvement by site managers at the planning stage would have assisted with managing expectations and role clarity during site visits.

While positive learning experiences have been associated with PBL, ${ }^{11-13}$ the satisfaction with the PBL and the rural retreat may be linked to the variety of learning modalities involved, including experiential learning - described elsewhere as 'significant' learning - as opposed to cognitive 'meaningless' learning. ${ }^{14}$ Such a mix would cater to the heterogeneity that exists in all groups, recognising that participants would not share the same learning style preference. $^{15}$

Satisfaction with the PBL appears to be derived in part from the study of a problem that requires active participation as opposed to problem simulation. ${ }^{4}$ The effectiveness of the PBL could also be due to the trainees being adult learners within a pre-existing well-formed group, which enabled them to quickly and productively focus on the topic. Because of the resources invested and the commitment by the trainees to be away from home, trainees may need to be 'made ready' for both the PBL and the retreat in order to maximise the learning opportunity. Not all groups may be as highly motivated or functional, so implementation issues, such as the level of problem structure and tutor directiveness, ${ }^{11}$ would need to be considered. Alternatively, the PBL might only be used where self-direction is assured. The model described, however, may work for other appropriately prepared public or primary health care staff involved in professional development.

\section{Conclusion}

Incorporating a public health PBL topic in a 1-week rural training retreat provides a positive learning experience for trainees undertaking postgraduate public health competency-based training. The value of a PBL within a rural retreat is linked to experiential learning where knowledge, insight and understanding are built with the potential to change individual practice and openness to work rurally. Rural educational retreats could play an important workforce role and should be considered for use with the range of health disciplines involved in such training.
A 1-week retreat with a single public health problem combined with good hospitality appears to be the right mix. Targeting motivated trainees at a level where they will be able to optimise the experience should be considered.

Preparatory work requires the design of a complex public health problem with appropriate site visits considered. Stakeholder involvement in planning will ensure roles are clear and expectations are managed. This style of learning should include orientation to the location and to the local public health unit staff so that trainees understand the organisational structures and resources available to practitioners. When evaluating the effectiveness of future public health training retreats, elements beyond learning domains should be considered, including the contextual elements of place and people. The question remains open as to whether this approach has a role in the broader implementation of the Program in both rural and non-rural settings.

To fully appreciate why this PBL was effective, comparative data from other rural training retreats involving PBL delivered for the Program is required. Such comparisons would identify the optimal range of sites and the suitability of public health problems.

\section{Acknowledgement}

The authors would like to thank all of the participants who contributed to the evaluation.

\section{References}

1. Hammel J, Royeen CB, Bagatell N, Chandler B, Jensen G, Loveland $\mathrm{J}$ et al. Student perspectives on problem-based learning in an occupational therapy curriculum: a multiyear qualitative evaluation. Am J Occup Ther 1999; 2: 199-206.

2. Mennin S, Gordan P, Majoor G, Osamn HAS. Position paper on problem-based learning. Educ Health (Abingdon) 2003; 16(1): 98-113. doi:10.1080/1357628031000066633

3. Norman GR, Schmidt HG. Effectiveness of problem-based learning curricula: theory, practice and paper darts. Med Educ 2000; 34: 721-8. doi:10.1046/j.1365-2923.2000.00749.x

4. Doucet MD, Purdy RA, Kaufman DM, Langille DB. Comparison of problem-based learning and lecture format in continuing medical education on headache diagnosis and management. Med Educ 1998; 32: 590-6. doi:10.1046/j.13652923.1998.00277.x

5. Pham KT, Blumberg P. Case design to emphasize population health concepts in problem-based learning. Educ Health (Abingdon) 2000; 13(1): 77-86. doi:10.1080/ 135762800110600

6. Spinello E, Fischbach R. Problem-based learning in public health instruction: a pilot study of an online simulation as a problem-based learning approach. Educ Health (Abingdon) 2004; 17(3): 365-73. doi:10.1080/13576280400002783

7. Fenwick T. Problem-based learning, group process and the mid-career professional: Implications for graduate education. Health Educ Res 2002; 21(1): 5-21. 
8. NSW Department of Health, Public Health Training and Development Unit. Informing public health practice competencies of the graduate diploma of applied epidemiology. State Health Publication No: (PHD) 000046. Sydney: NSW Department of Health, 2000.

9. Dolmans DHJM, DeGrave W, Wolfhagen IHAP, Van der Vleuten CPM. Problem-based learning: Future challenges for educational practice and research. Med Educ 2005; 39(7): 732-41. doi:10.1111/j.1365-2929.2005.02205.x

10. Nesbit T. Mapping adult education. Educ Theory 1999; 49(2): 265-79. doi:10.1111/j.1741-5446.1999.00265.x

11. Albanese M, Mitchell S. Problem-based learning: a review of literature on its outcomes and implementation issues. Acad Med 1993; 68(1): 52-81. doi:10.1097/00001888-19930100000012
12. Berkson L. Problem-based learning: have the expectations been met? Acad Med 1993; 68(Suppl): S79-88. doi:10.1097/00001888-199310000-00053

13. Vernon D, Blake R. Does problem-based learning work? A meta-analysis of evaluative research. Acad Med 1993; 68: 550-63. doi:10.1097/00001888-199307000-00015

14. Rogers C. Learning theories: Experiential learning. Available at http://www.educationau.edu.au/archives/cp/04f.htm. Accessed 24 February 2006.

15. Conner ML, Wright KC, DeVries L, Zeider C, Wilmsmeyer D, Forman D. Learning: the critical technology. Missouri: Wave Technologies International Inc., 1996. Available at www.wavetech.com/abt/abttmwp.htm. Accessed 1 August 2006.

\section{Use of communication technology among public health professionals in New South Wales, Australia}

\section{Carlie-Jane Naylor ${ }^{\mathrm{A}, \mathrm{C}}$, D. Lynne Madden ${ }^{\mathrm{A}}$ and Deborah J. Oong ${ }^{\mathrm{B}}$}

APublic Health Training and Development Branch, NSW Department of Health

${ }^{\mathrm{B}}$ Corporate Governance and Risk Management Branch, NSW Department of Health

${ }^{\mathrm{C}}$ Corresponding author.Email: carlie.naylor@doh.health.nsw.gov.au

\section{Introduction}

Communication technology plays an important role in health services in NSW, not only for the delivery of clinical services but also as a means of delivering training, holding meetings and sustaining networks. One reason for this is the large geographical size of NSW; it is divided into eight area health services, the largest of which covers $444586 \mathrm{~km}^{2}{ }^{1}$ Communication technology provides a means of linking health professionals across areas, and is particularly useful for those working in rural and remote communities. Even where distances are not large, these techniques also allow a more efficient use of time by reducing the need for travel.

Teleconferencing is frequently used for different types of meetings because it is readily available and easy to use. These features led Wildsoet et al. ${ }^{2}$ to pilot a continuing eduction program via teleconferencing to optometrists in rural Queensland. There are, however, limitations to teleconferencing. A randomised controlled trial compared teleconferencing with videoconferencing for the delivery of multidisciplinary case conferences. ${ }^{3}$ The trial found that there were more benefits with videoconferencing, and a small survey conducted with trial participants highlighted that having a visual component generated a high level of satisfaction in team members.

Videoconferencing is widely used in medicine for delivering clinical services such as mental health. ${ }^{4}$ In these clini- 
Table 1. Six communication techniques used in the survey of the public health workforce

\begin{tabular}{ll}
\hline Technique & Description \\
\hline $\begin{array}{l}\text { Teleconference } \\
\text { Web bulletin boards }\end{array}$ & $\begin{array}{l}\text { Interactive exchange of voice, usually of more than two participants, by telephone } \\
\text { Eeb conference }\end{array}$ \\
$\begin{array}{l}\text { Conducted over the Internet between two or more people situated at different locations; enables } \\
\text { videos, websites, PowerPoint presentations and software demonstrations to be displayed in real time to } \\
\text { all participants }\end{array}$ \\
$\begin{array}{l}\text { Tideoconference } \\
\text { Media streaming }\end{array}$ & $\begin{array}{l}\text { Transmission of video with synchronised sound in compressed form over the Internet to be viewed as a } \\
\text { continuous stream }\end{array}$ \\
Satellite television & A live broadcast over a satellite network \\
\hline
\end{tabular}

cal settings, there are two sites: one where the clinician is based and the other a remote site where the patient is located. This type of videoconference is referred to as point-to-point. Videoconferencing can also be used to deliver continuing professional development activities to multiple remote sites while retaining an environment that supports collegiate networking. ${ }^{5}$

Streaming media over the Internet provides a solution when training schedules conflict with other commitments. Chong et al. described their experience of setting up and delivering presentations by media streaming to pharmacy staff at a Vancouver hospital. Staff who were unable to attend the face-to-face sessions were able to access the presentations at their own convenience, either on their work or home computer. ${ }^{6}$ Other computer-based applications, such as web conferencing and web bulletin boards, offer alternative ways to support the delivery of training.

Another effective medium for delivering continuing education to large groups is satellite television. The Centers for Disease Control and Prevention (CDC) have used this medium to deliver courses to multiple sites across the United States. ${ }^{7,8}$

There may be opportunities to expand the contribution of communication technology to public health work. In order to inform strategic planning for the public health workforce and identify opportunities to use communication technology, a survey was undertaken to provide a 'snapshot' of the current use of communication techniques by public health professionals. The forms used, the situations in which these are applied and the level of use were explored.

\section{Methods}

Thirteen senior public health professionals working within the NSW Department of Health and/or area health services were invited to participate in the survey. Participants from the area health services were chosen from the population health structures, including health promotion units and public health units. A community health perspective was also sought. Three participants were drawn from the Division of Population Health of the NSW Department of Health. Two of the 13 public health professionals who were invited to participate were drawn from rural areas and the remainder from metropolitan areas.

A three-part, structured questionnaire with closed and open-ended questions was designed for the survey. The first part sought characteristics of the participants and their work. As two of the most common applications of communication technology are to conduct meetings and to deliver professional development activities, estimates of the amount of time spent in these activities were sought. The second part asked about the participants' experience of using six techniques, teleconferencing, web bulletin boards, web conferencing, videoconferencing, media streaming and satellite television, and their interest in expanding their experience. The third part explored factors that would prevent or assist them in using these techniques.

The interviews were conducted in March and April 2005. The questionnaire was administered to the participants by the same interviewer, either in person or over the telephone. Before commencing the interview with each participant, the interviewer established the context and the scope for the interview with a scripted preamble. Recognising that not all the participants would be familiar with the techniques being investigated, the interviewer used standardised descriptions of each type of communication technique (Table 1). The survey and preamble were piloted with a public health professional, and the feedback was used to amend the questionnaire and its delivery.

Responses were entered into a database created in Epi Info version 3.3 (CDC, Atlanta, GA, USA). For the closed questions, frequencies were reported. A thematic analysis was carried out on the responses to the open-ended questions. 


\section{Results}

\section{Characteristics of the participants}

Twelve of the 13 public health professionals agreed to be interviewed (response rate, 92\%). The roles and responsibilities of the participants spanned managing units or teams; leading population health and community services; development of evidence-based guidelines and policies; workforce development; facilitating health promotion; and the provision of population health services. The number of people reporting to individual participants varied from one full-time equivalent position to about 1000 (through direct and indirect reporting lines).

The amount of participants' time taken up with meetings and/or delivering professional development activities ranged from 20 to $80 \%$. The amount of time that participants reported they spent travelling to these activities varied from 'very little', with meetings being held at their worksite, to about 2 hours a day. Five participants indicated that the amount of time dedicated to travelling to meet with staff and fulfil other organisational functions was likely to increase as a result of the restructuring of health services in NSW.

\section{Experience of communication technology}

All 12 participants reported using teleconferencing and 11 were familiar with videoconferencing. The three computer-based modalities and satellite television had been used by only a few participants.

The techniques were most commonly used for continuing professional development, meetings, interview panels and collaboration. Videoconferencing and teleconferencing were used for the widest range of activities, whereas web bulletin boards were primarily used for disseminating information to staff. While a couple of individuals used a wide range of techniques, no individual used all forms.

Circumstances often determined when the technology was used. For example, teleconferencing was used when the distance to travel for a face-to-face meeting was prohibitive or when an urgent issue had to be addressed at short notice. One participant, who described face-to-face meetings as the 'ideal', considered that videoconferencing provided a way to meet in real time when that ideal was not possible.

\section{Barriers and enabling factors}

Enabling factors that promoted the use of these techniques were: ease of access to facilities; assistance in organising and setting up the technology; the perception that the technology allowed efficient and effective use of time; and suitability of the technique for the intended purpose. Communication technology was viewed as a potentially cost-effective way of providing training opportunities for staff and limiting the need to travel.
The barriers to using these communication techniques were: difficulty in accessing the equipment; perceived difficulty in setting up and operating the equipment; and cost of use. Participants considered that skill and expertise are required to use these techniques successfully. They also reported having limited knowledge about use of many of them and lack of familiarity with the variety of techniques potentially available and their applications.

Nine participants indicated that there were opportunities to expand use of these techniques in the workplace. Suggestions included the delivery of training, the dissemination of information, working collaboratively, and exploring ways of combining use of these techniques with face-to-face delivery.

\section{Discussion}

Two techniques, teleconferencing and videoconferencing, are well established in practice. All participants used teleconferencing, and most used it frequently in everyday practice as it was seen as being easy to use and accessible. The advantage of videoconferencing over teleconferencing was the opportunity for personal contact and visual cues, features that were valued when higher levels of engagement were required. Satellite television was reserved for continuing professional development activities with large groups because of the costs associated with its delivery.

This survey was carried out with a small, selected group of public health professionals, so while the findings provide an insight into the current use of communication technology across a broad range of pubic health practice, they are indicative only. Further, the survey asked about current and potential use of these techniques. Information about the difficulties being experienced in their use was not sought. Consequently, the nature of the questions might have shaped both the information collected and the positive response of the participants.

Generally, the participants used what was familiar to them or had been recommended by colleagues. Having knowledge about and skills in the use of a technique appeared to lead to its routine application. However, familiarity alone did not determine whether a technique was used and a judgement was made about whether it was appropriate for the task. The efficient use of time and positive outcomes from the experience encouraged future use. Conversely, poor-quality interactions were discouraging, particularly when there was a choice for how a task was managed. Participants were clear about the factors that helped them to engage with these techniques, and they were discerning in their use.

Many participants raised cost as an issue, inferring that techniques that were cheap were more likely to be used. 
However, there can be a trade-off between cost and quality of delivery. For example, for videoconferencing, better quality transmission is associated with higher cost and cheaper options might be a false economy. There are nevertheless potential savings to be gained by the health system in using communication technology, in particular to reduce costs associated with travel.

Use of these techniques expands the size of the population that can potentially participate in activities, for example, meetings, training and mentoring, providing opportunities that would otherwise not have been available. For many of these individuals, face-to-face attendance at these events is not an option so their participation through the use of communication technology may present an additional cost to the system.

A review of the NSW Public Health Network presented in 2006 suggested that greater use could be made of communication technology to maintain collegiate networks and deliver public health functions. ${ }^{9}$ A response to this prepared by Directors of Public Health in NSW acknowledged increased reliance on communication technology while identifying many of the barriers to use described in this survey. In addition to those barriers that exist at the organisation level, effort is also required by individuals to change the way they use communication technology.

To encourage use of these techniques, ways to minimise the barriers and ensure high-quality interactions should be explored. As teleconferencing and videoconferencing are the most commonly used techniques, a priority should be to ensure that they are used effectively to support public health functions.

\section{Conclusion}

This sample of population health professionals engaged enthusiastically in considering how use of communication technology might be expanded to support population health work. These techniques enable remote collegial networks and continuing professional development. Information from this survey was used as a basis for a sub- mission by the Division of Population Health for Telehealth funding in 2005-06. A report of this survey, including the questionnaire, will be published as a supplement to the NSW Public Health Bulletin.

\section{Acknowledgements}

We would like to thank the participants of this survey. We would also like to thank the anonymous reviewers and Elisabeth Heseltine for their comments and suggestions on ways to improve this manuscript.

\section{References}

1. Greater Western Area Health Service. Greater Western Area Health Service Annual Report 2004/05. Available at www.gwahs.nsw.gov.au/files/AReport_Web_Version.pdf. Accessed 18 March 2007.

2. Wildsoet C, Wood J, Parke J. Audio-teleconferencing as a medium for distance learning: its application for continuing education in optometry. Aust J Rural Health 1996; 4(1): 18-27.

3. Wilson SF, Marks R, Collins N, Warner B, Frick L. Benefits of multidisciplinary case conferencing using audiovisual compared with telephone communication: a randomized controlled trial. J Telemed Telecare 2004; 10(6): 351-4. doi:10.1258/1357633042602026

4. Dossetor DR, Nunn KP, Fairley M, Eggleton D. A child and adolescent psychiatric outreach service for rural New South Wales: a telemedicine pilot study. J Paediatr Child Health 1999; 35(6): 525-9. doi:10.1046/j.1440-1754.1999.00410.x

5. Madden DL, Naylor CJ, Simpson D. An evaluation of videoconferencing Bug Breakfast. NSW Public Health Bull 2003; 14: S-2.

6. Chong E, Balen RM, Jewesson PJ. Delivery of multimedia educational presentations via streaming media. Am J Health Syst Pharm 2003; 60(23): 2475-8.

7. Maetz HM, Walton W, Smith M, Lincoln R, Galvin M, Tryon C et al. "A satellite primer on tuberculosis": a collaboration in distance education. J Public Health Manag Pract 1998; 4(5): 46-55.

8. Umble KE, Cervero RM, Yang B, Atkinson WL. Effects of traditional classroom and distance continuing education: a theory-driven evaluation of a vaccine-preventable diseases course. Am J Public Health 2000; 90(8): 1218-24.

9. Morey S. Review of the NSW Public Health Network. Final report. [Internal NSW Health Report]. Morey Australia, March 2006. 


\section{Influencing population health performance: introduction of standards for area health}

services in New South Wales

\author{
Jeannine Liddle ${ }^{\mathrm{A}, \mathrm{B}, \mathrm{F}}$, David Lyle ${ }^{\mathrm{A}, \mathrm{C}}$, \\ Margaret Lesjak $^{\mathrm{A}, \mathrm{D}}$, Andrew Milat $^{\mathrm{A}, \mathrm{E}}$, \\ Emma Webster $^{\mathrm{A}, \mathrm{B}}$ and Thérèse Jones ${ }^{\mathrm{A}, \mathrm{B}}$ \\ A Greater Western Area Health Service Population Health \\ Standards Evaluation Group. \\ BPopulation Health, Planning and Performance, \\ Greater Western Area Health Service. \\ ${ }^{\mathrm{C}}$ Broken Hill University Department of Rural Health, \\ University of Sydney. \\ ${ }^{\mathrm{D} B r o k e n ~ H i l l ~ C e n t r e ~ f o r ~ R e m o t e ~ H e a l t h ~ R e s e a r c h ~-~ J o i n t ~ I n i t i a t i v e ~}$ \\ of the University of Sydney and Greater Western Area Health \\ Service. \\ ${ }^{\mathrm{E}}$ Centre for Chronic Disease Prevention and Health Advancement, \\ NSW Department of Health. \\ ${ }^{\mathrm{F}}$ Corresponding author: jeannine.liddle@gwahs.health.nsw.gov.au
}

\begin{abstract}
Standards are a yardstick against which performance can be assessed and improved. Standards are well established in healthcare settings; however, population health standards have only recently been developed for area health services in NSW. This paper describes international and Australian population health standards, and presents the results of a pilot evaluation of the NSW Population Health Standards for Area Health Services against the Greater Western Area Health Service performance requirements. The findings revealed that the standards relating to the work of specialist population health staff feature in performance requirements; however the standards requiring the contribution of other health service staff do not. Population health standards have the potential to guide the health system towards population health goals.
\end{abstract}

The goals of the NSW health system encompass a commitment to improve the health of the whole population and to reduce health inequalities between population groups. ${ }^{1}$ These goals can be realised by embedding a population health approach at both strategic and operational levels. Key elements of this approach include:
- use of population health data to inform service planning,

- utilising the best available evidence to inform policy and program development,

- addressing the determinants of health and their interactions,

- collaborating across sectors and involving stakeholders to achieve tangible outcomes,

- building and maintaining capacity for action through workforce development and budgetary investments and

- being accountable to the public for what health outcomes are achieved.

A population health approach should therefore: be core business for health planners and population health practitioners; be integral to the work of primary health care providers; and influence the operations of the acute care sector.

A set of population health standards which focus on the promotion, protection and maintenance of the health of the community is a potential means for improving organisational performance in population health and demonstrating that the NSW health system's obligations to the people of NSW have been met. Since the mid 1990s, there have been efforts to define and measure population health performance in Australia, the USA, Canada and the United Kingdom (UK). In 2004, the NSW Department of Health began developing the Population Health Standards for Area Health Services (the Standards).

This paper reports on the development of the Standards and assesses how well they are reflected in current area health service performance requirements.

\section{Development of population health standards}

Peer-reviewed literature on this subject was identified through electronic databases (Medline, PubMed, Journals@Ovid Full Text). The grey literature was identified through Internet searching using Google and by searching specific websites including Public Health Agency of Canada, Department of Health (UK), Centers for Disease Control and Prevention (USA) and National Public Health Partnership (Australia). Additional literature was sourced from experts in the population health field and reference lists from relevant articles and reports. 


\section{International experience}

Most peer-reviewed literature in this field originates from the USA, where processes to develop and introduce a national set of performance standards for public health practice commenced in $1997 .{ }^{2}$ In the USA, the term 'public health' is used rather than 'population health'. The USA standards are based on '10 Essential Public Health Services' and link to the core functions of public health: assessment, policy and assurance. ${ }^{3}$ The standards apply to the public health system as a whole and recognise the influence of community members and partner organisations on health system performance. Three instruments covering State Public Health Systems, Local Public Health Systems and Local Public Health Governance are used to assess performance against these standards. ${ }^{4}$

In England and Wales, a new performance framework is being implemented, driven by Standards for Better Health which sets out the level that all organisations providing National Health Service care are expected to meet. ${ }^{5}$ Standards for public health are included. A process for measuring performance using the standards was introduced in 2005-2006.

The Canadian government identified population health as a 'key concept and approach for policy and program development aimed at improving the health of Canadians'. ${ }^{6}$ A population health template was developed that set out current understandings of population health, outlined processes required to implement a population health approach and gave guidance on assessing preparedness and capacity to implement. The template was presented as a resource for policy makers, program planners, health educators, evaluators, grant reviewers and writers, researchers and academics. It was not presented as a set of standards, although the conceptual model and content could have formed a basis for standards within the Canadian health system.

\section{Australian experience}

In Australia, the former National Public Health Partnership facilitated discussion on improving the quality of public health practice ${ }^{7,8}$ and produced resource documents. ${ }^{9,10}$ The partnership commissioned the National Delphi Study on public health functions to identify a 'common reference point for any exercise where a standard definition of public health is needed, for example when developing performance measures and standards, or examining whether core functions are being delivered to acceptable standards'. ${ }^{11}$ The study led to a statement of core functions for current public health practice in Australia. ${ }^{12}$ The 2006 edition of the Evaluation and Quality Improvement Program (EQuIP) standards, produced by the Australian Council on Healthcare Standards, has for the first time, included one specific population health standard: 'the organisation promotes the health of the population'. ${ }^{13}$

\section{NSW developments}

In 2004, the Population Health Division of the NSW Department of Health convened a group of population health experts to consider a range of documents on population health standards, performance management and program evaluation, and develop a draft version of the Standards. They used the Occupational Health Safety and Rehabilitation Numerical profile ${ }^{14}$ and the EQuIP standards ${ }^{15}$ as a guide for the structure. Comment was sought from stakeholders, including those from the NSW Department of Health, area health services, Senior Executive Advisory Board, NSW Public Health Forum and Australian Council on Healthcare Standards.

The final version of the Standards, completed in late 2005, consisted of 17 individual standards organised under six functions (Box 1). The Greater Western Area Health Service (GWAHS) agreed to conduct a pilot assessment and evaluation of the Standards.

\section{GWAHS pilot evaluation}

GWAHS set up an evaluation group in March 2006 with representation from GWAHS, Broken Hill Department of Rural Health University of Sydney and the Centre for Chronic Disease Prevention and Health Advancement, NSW Department of Health. The relevance and acceptability of the Standards and practicalities of assessment were to be determined by:

- mapping the Standards to the 2005/2006 GWAHS Performance Agreement and Population Health Service Agreement and describing the degree to which these performance requirements address each standard (presented in this paper),

- describing the extent to which the Standards relate to the National Public Health Partnership Statement of Core Functions ${ }^{12}$ and

- documenting the views of area health service staff regarding the Standards, their application to GWAHS and the assessment process (to be presented in a subsequent paper).

\section{Mapping the Standards to GWAHS performance requirements}

Area health service performance agreements and service agreements specify the key roles, responsibilities and deliverables for the NSW Department of Health and area health services. Each standard was compared with the 2005/2006 GWAHS Performance Agreement and GWAHS Population Health Service Agreement. Three categories were used to describe the extent to which the Standards are reflected in formal performance requirements:

- high, i.e. standard is reflected in performance requirements;

- medium, i.e. standard is partly reflected through performance indicators/targets; 


\section{Box 1. Population health standards for area health services (AHS)}

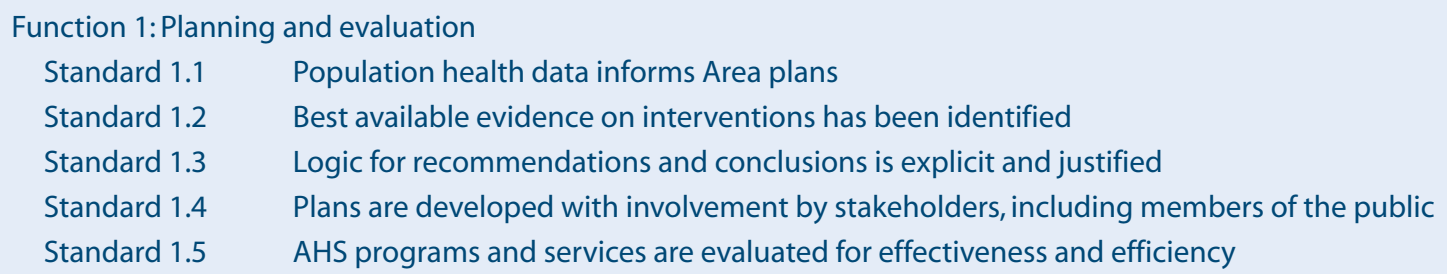

Function 2: Surveillance and monitoring

Standard 2.1 Area maintains sensitive systems for early detection and monitoring of health hazards and determinants

Standard 2.2 Effective infectious disease surveillance in place

Function 3: Health promotion

Standard 3.1 Area undertakes evidence-based, priority driven, outcome oriented primary prevention activities

Standard 3.2 Area undertakes evidence-based, priority driven, outcome oriented secondary prevention activities

Standard 3.1 Area undertakes evidence-based, priority driven, outcome oriented tertiary prevention activities

Function 4: Health protection

Standard 4.1 Outbreaks of illness, clusters of disease and health hazards are investigated and responded to in a timely and effective way

Standard 4.2 Health protection regulatory obligations are effectively and efficiently discharged

Standard 4.3 Arrangements for public health input to disaster management are in place, tested and are effective when deployed

Function 5: Effective partnerships

Standard 5.1 AHS maintains effective partnerships to optimise service and program delivery

Function 6: Resource management

Standard 6.1 AHS has an appropriate workforce to undertake population health activities

Standard 6.2 AHS has training and support systems in place to optimise and retain its workforce

Standard 6.3 Area population health budget is commensurate with population health needs and targets

- low, i.e. standard is not considered or indicators/targets do not enable assessment of performance against the standard.

Categories were initially applied by one of the authors (JL), then discussed and agreed by the evaluation group. Table 1 outlines the results.

Overall, the mapping process found that the Standards which are reflected in current performance requirements are those that relate most closely to the work of specialist population health staff (for example, surveillance and monitoring, health protection, and primary prevention). The Standards that require the contribution of other health service staff to be realised, for example, the Standards that related to planning, partnerships, resource management, secondary and tertiary prevention activities, and evaluation, are not so well reflected in current performance requirements.

'Equity' was referred to in all three documents but the indicators and targets that would be needed to monitor performance were lacking in the performance requirements. 'Access' was referred to in the performance agreement but not developed further and not considered in the Standards.

\section{Discussion}

Embedding a population health approach at both strategic and operational levels requires the commitment and involvement of health service staff throughout the system. If the population health approach of the NSW health system is confined to the work of specialist population health, then the twin goals of improving the health of the whole population and reducing health inequalities between population groups will not be met.

Standards can relate to infrastructure (such as personnel or budget), processes (such as services or interventions) or outcomes (such as mortality or morbidity). ${ }^{16}$ Depending on the maturity of the system or organisation to which standards are applied, emphasis may be placed on infrastructure (for newly formed systems) or outcomes (for mature systems). ${ }^{17}$ The Standards currently focus on infrastructure and processes. In contrast, standards applied to health care settings have shown a recent shift in emphasis to outcomes. ${ }^{18}$ Future iterations of the Standards may follow the same trend. When using the Standards to assess performance at the organisational level, differences in organisational development also need to be acknowledged when interpreting, and in particular, if comparing, assessment results. 
Table 1. Extent to which Population Health Standards for Area Health Services are reflected in 2005/2006 GWAHS performance requirements

\begin{tabular}{lll}
\hline Population Health Standards & $\begin{array}{l}\text { GWAHS Performance } \\
\text { Agreement }^{A}\end{array}$ & $\begin{array}{l}\text { GWAHS Population Health Service } \\
\text { Agreement }^{\mathrm{A}}\end{array}$ \\
\hline Planning standards (1.1-1.4) & Low & Medium \\
Evaluation standard (1.5) & Medium & Medium \\
Surveillance and monitoring standards (2.1-2.2) & Medium & High \\
Health promotion standards (3.1-3.3) & Medium & High \\
Health protection standards (4.1-4.3) & High & High \\
Partnerships standard (5.1) & Low & Low \\
Resource management standards (6.1-6.3) & Low & Medium \\
\hline
\end{tabular}

ALow, standard is not considered or indicators/targets do not enable assessment of performance against the standard; medium, standard is partly reflected through performance indicators/targets; high, standard is reflected in performance requirements

Standards in population health have been used for improving quality of population health services, for enhancing accountability and for strengthening the evidence base of population health practice. ${ }^{19,20}$ If standards are to be used effectively for performance accountability, the following are required: 21

- training and technical assistance to conduct assessments,

- suitable surveillance systems to collect and analyse assessment data,

- participation of community and partner organisations in assessment,

- direction on how to use assessment results to improve performance and

- ongoing research on relationships between infrastructure, process and outcome.

Standards need an underpinning conceptual framework which adequately defines components of the population health system and how they fit together. ${ }^{19}$ The task of defining the system and its component parts is difficult when population health in Australia continues to evolve. ${ }^{22}$ The Standards implicitly draw on the National Public Health Partnership Statement of Core Functions and understandings of a 'population health approach'. The draft Healthy People 2010: the Population Health Plan for New South Wales sets out one framework. ${ }^{23}$ Further work is required to refine the framework of the Standards, so that they fit with the NSW health system in a clear, relevant and meaningful way.

Area health services form only part of the health system in NSW. Population health standards are relevant to all parts of the system, including the NSW Department of Health. In the USA, public health standards apply at both state and local levels. ${ }^{4}$

The area health service performance agreements set down health system priorities. Population health priorities need to be on that agenda and population health standards have a role in guiding that agenda. Standards which clearly describe where the system needs to be putting effort in population health, and the associated performance requirements, indicators and targets, would assist development of future performance agreements. Population health standards have the potential to focus debate, provide consistent language and lead to a system-wide and integrated approach to making population health 'everybody's business'. ${ }^{24}$

\section{Conclusion}

Population health standards can assist in embedding population health in the business of the health system at the policy, operational and individual practice levels. However, international experience shows that to use population health standards on a system wide basis and to assess performance against these standards, considerable investment is needed to support implementation and to engage partner organisations and communities in the process.

\section{Acknowledgements}

The authors wish to acknowledge Ross O'Donoughue and the members of the original working group who developed the Population Health Standards for Area Health Services: Peter Sainsbury, Jeanette Ward, Mark Ferson and Sarah Thackway.

\section{References}

1. NSW Department of Health. Annual report 04/05. Available at www.health.nsw.gov.au/pubs/2005/pdf/ar2005.pdf. Accessed 2 August 2006.

2. Bakes-Martin R, Corso LC, Landrum LB, Scott Fisher V, Halverson K. Developing national performance standards for local public health systems. J Public Health Manag Prac 2005; 11(5): 418-21.

3. Public Health Functions Project Steering Committee. Public health in America. Available at www.health.gov/phfunctions/public.htm. Accessed 29 June 2006.

4. Office of the Director National Public Health Performance Standards Program, Centers for Disease Control and 
Prevention. The instruments. Available at www.cdc.gov/od/ocphp/nphpsp/TheInstruments.htm. Accessed 29 June 2006.

5. Department of Health. Standards for better health. April 2006. Available at www.dh.gov.uk. Accessed 2 August 2006.

6. Population and Public Health Branch Strategic Policy Directorate, Public Health Agency of Canada. The population health template: key elements and actions that define a population health approach. Draft. July 2001, p. 1. Available at www.phac-aspc.gc.ca/ph-sp/phdd/approach/index.html. Accessed 29 June 2006.

7. Diagnosis Pty Ltd. Quality systems and public health: background review. Excerpt from report to the National Public Health Partnership. October 1998. Melbourne: NHPH, 1998. Available at www.dhs.vic.gov.au/nphp/publications/ phpractice/qualbgreview.pdf. Accessed 8 May 2006

8. National Public Health Partnership. Promoting quality in public health. Report of workshop held in Sydney on 6 December 1999. Melbourne: NHPH, 1999. Available at www.dhs.vic.gov.au/nphp/publications/phpractice/forum.pdf. Accessed 8 May 2006.

9. National Public Health Partnership. A planning framework for public health practice. September 2000. Melbourne: NHPH, 2002. Available at

www.dhs.vic.gov.au/nphp/publications/phpractice/planfrwk.pdf. Accessed 18 January 2006.

10. Rychetnik L, Frommer M. A schema for evaluating evidence on public health interventions; Version 4. Melbourne: NHPH, 2002. Available at www.nphp.gov.au/publications/phpractice/ schemaV4.pdf. Accessed 18 January 2006.

11. National Public Health Partnership. National Delphi study on public health functions in Australia. Report on findings. January 2000. Melbourne: NHPH, 2002. p. 39. Available at www.dhs.vic.gov.au/nphp/publications/phpractice/ delphi-body.pdf. Accessed 8 May 2006.

12. National Public Health Partnership. Public health practice in Australia today. A statement of core functions. September 2000. Melbourne: NHPH, 2000. Available at www.nphp.gov.au/workprog/phpractice/corefuncts.htm. Accessed 8 May 2006.

13. The Australian Council on Healthcare Standards (ACHS). The ACHS EQuIP 4 Guide, Part 1 -Accreditation, standards, guidelines. Sydney: ACHS, 2006. p. 196.
14. NSW Department of Health. Occupational health, safety and rehabilitation numerical profile PD2005_189. 2005. Available at www.health.nsw.gov.au/policies/PD/2005/ PD2005_189.html. Accessed 2 August 2006.

15. The Australian Council on Healthcare Standards (ACHS). The EQuIP Corporate (Health Services) Guide. 2nd Edn. Sydney: ACHS, 2003.

16. Donabedian A. Explorations in quality assessment and monitoring. Vol 1: The definition of quality and approaches to its assessment. Ann Arbour, MI: Health Admin. Press, 1980.

17. Derose SF, Schuster MA, Fielding JE, Asch SM. Public health quality measurement: concepts and challenges. Annu Rev Public Health 2002; 23: 1-21. doi:10.1146/annurev.publhealth.23.092601.095644

18. Skok A, Swerissen H, Macmillan J. Standards and quality improvement processes in health and community services: a review of the literature. June 2000. Bundoora, Vic.: Quality Improvement Council Ltd, 2000. Available at www.qic.org.au/Docs/Lit_review.pdf. Accessed 16 November 2006.

19. Turnock B, Handler A. From measuring to improving public health practice. Annu Rev Public Health 1997; 18: 261-82. doi:10.1146/annurev.publhealth.18.1.261

20. Handler A, Issel M, Turnock B. A conceptual framework to measure performance of the public health system. Am J Public Health 2001; 91: 1235-9.

21. Beaulieu JE, Scutchfield FD, Kelly AV. Recommendations from testing of the National public health performance standards instruments. J Public Health Manag Prac 2003; 9(3): 188-98.

22. Gruszin S, Jorm L, Churches T, Straton J. Public health classifications project phase one: final report. Melbourne: National Public Health Partnership, 2006.

23. Public Health Division. Healthy people NSW: Improving the health of the population. Sydney: NSW Department of Health, 2007.

24. NSW Department of Health. Fit for the future: have your say about future directions for health in NSW, 2006. Available at www.health.nsw.gov.au/futuresplanning/. Accessed 2 August 2006. 


\section{Health surveillance among a team of Australian health workers assisting tsunami victims in Aceh, Indonesia}

\author{
Jeremy M. McAnulty ${ }^{\mathrm{A}, \mathrm{B}, \mathrm{C}}$ and Michael Flynn ${ }^{\mathrm{B}}$ \\ ${ }^{\mathrm{A} N S W}$ Department of Health. \\ ${ }^{\mathrm{B}}$ On behalf of: Combined Australian Surgical Team - Aceh. \\ ${ }^{\mathrm{C}}$ Corresponding author. Email: \\ jeremy.mcanulty@doh.health.nsw.gov.au
}

\begin{abstract}
Objective: To determine the extent and nature of health-related behaviours and outcomes among members of the first foreign medical team to arrive in Aceh, following the Boxing Day tsunami in 2004. Methods: A cross sectional survey of team members 4 weeks after return from Aceh. Results: Compliance with antimalarial chemoprophylaxis and insect repellent was high while in Aceh, but only one-third completed the course of chemoprophylaxis. The provision of prepackaged food and water was likely to have prevented enteric disease. Members reported mosquito bites, fatigue, sunburn, headache and anxiety about earthquakes. Conclusions: Provision of prepackaged food and water, preventive measures and information to members may be important in avoiding illness in such teams.
\end{abstract}

Following the Asian tsunami of 26 December 2004, the Australian Government dispatched several medical teams to affected regions to assist in the care and treatment of injured people. Two of these teams (Teams Alpha and Bravo) were combined and sent to Aceh, a province in Indonesia. This group became the Combined Australian Surgical Team - Aceh (CASTA).

CASTA had 28 members. It was led by one of the authors (Michael Flynn) and included a deputy leader, two logisticians (fire officers), two medical logisticians, two paramedics, an infectious diseases doctor, an emergency doctor, four anaesthetists, two general surgeons, two orthopaedic surgeons, four theatre nurses, four emergency nurses and two public health doctors. CASTA team members gathered in Sydney on Wednesday 29 December and were briefed on the general situation and likely health risks. They were provided with daily doxycycline tablets for malaria prophylaxis and offered immunoglobulin if they were not known to be immune to hepatitis A and typhoid vaccine if they had not been vaccinated against typhoid in the previous 3 years. CASTA left from the Royal Australian Air Force Base, Richmond, that afternoon and stayed in Jakarta overnight.

On 30 December CASTA members flew to Banda Aceh (a city in Aceh) and stayed overnight near the airfield in tents. On 31 December, trucks carried team members to the Fakinah Hospital, a private hospital that had experienced only mild earthquake damage and was not affected by water from the tsunami. Fakinah Hospital had been reopened and had a small number of surgical staff who had been flown in from other parts of Indonesia. However, medical supplies and staffing levels were limited.

CASTA team members provided an acute surgical and medical service at Fakinah Hospital, Kesdam Hospital (also in Banda Aceh, and to which surgical teams travelled each day) and Sigli Hospital (outside Banda Aceh, and to which a small team travelled in the latter part of their time in Aceh, to assist a Médecins Sans Frontières surgical team). From 31 December 2004 to 6 January 2005, the CASTA team cared for patients attending the Fakinah Hospital emergency department, providing medical care to around 75 inpatients at the Fakinah Hospital, performing surgical procedures for over 130 patients and providing treatments to many other patients at all three hospitals. CASTA left Banda Aceh for Jakarta on Friday 7 January 2005, departed Jakarta on 8 January and returned to Australia on the morning of 9 January.

While in Banda Aceh, team members were provided with bottled water and prepackaged food (in the form of military ration packs) brought from Australia, bed nets, insect repellent and other personal protective equipment. Team members were reminded to use these on a daily basis.

This study aimed to identify whether CASTA team members complied with the preventive advice above and also to assess team members' health status while on the mission and in the 4 weeks following their return to Australia. In addition, team members' suggestions were sought for improving prevention for future such missions. 


\section{Methods}

CASTA team members agreed to participate in a cross sectional survey at one of the regular evening debriefs while they were in Banda Aceh. A questionnaire was developed in consultation with team members. It covered their demographic characteristics, past experience of overseas relief missions, use of prophylactic materials (such as repellents and sun block), symptoms experienced on mission and comments on how their health could have been improved. The questionnaire was emailed to all team members on 4 February 2005 (4 weeks after leaving Aceh), and two follow up emails were sent to members soliciting completed questionnaires. Team members faxed or emailed responses to the other author (Jeremy McAnulty) who deidentified, collated and tallied the responses.

\section{Results}

In total, $22(79 \%)$ of the 28 CASTA members returned completed questionnaires. The main functions of these 22 respondents were: clinical (17), public health/administra- tion (three) and support/logistics (two). Average age was 48 years (range 35 to 58 years) and $16(73 \%)$ were male. Ten $(45 \%)$ reported previous experience in overseas relief missions.

Table 1 displays the number and per cent of respondents who reported compliance with the preventive measures while they were on the mission, as well as their reported health problems and concerns. No one reported vomiting, diarrhoea or fever. Of the seven reported injuries, two were directly health care associated (eye splash and needle stick), and five were less direct (strained back, small scratches, stab wound while making holes in bottles, scratches from a cat that led to a course of rabies vaccination, and a painful knee).

\section{Health after returning home}

Eight respondents $(36 \%)$ reported that they had missionrelated health problems on return. These included skin problems such as itchiness, ringworm and presumed solar sensitivity to doxycycline (three); sleep, concentration or

Table 1. Number and percentage of Combined Australian Surgical Team - Aceh (CASTA) members reporting compliance with preventive measures, and health problems and concerns while on mission, January $2005(n=22)$

\begin{tabular}{lcc}
\hline & $n$ & $\%$ \\
\hline Compliance with preventive measures & & \\
Received immunoglobulin on day of departure & 10 & 45 \\
Received typhoid vaccine on day of departure & 13 & 59 \\
Took doxycycline daily while on mission & 22 & 100 \\
Took doxycycline for recommended 4 weeks after return & 7 & 32 \\
Applied insect repellent every day & 20 & 91 \\
Applied sun block every day & 4 & 18 \\
Reported health problems while on mission & & \\
Bitten by mosquitoes (2-10 times) & 14 & 64 \\
Fatigue & 13 & 59 \\
Sunburn (not severe) & 8 & 36 \\
Headache & 7 & 32 \\
Sustained an injury & 7 & 32 \\
Anxiety & 5 & 23 \\
Nausea & 3 & 14 \\
Constipation & 1 & 5 \\
Depression & 1 & 5 \\
Thrush & 1 & 5 \\
Stye & 1 & 5 \\
Upper respiratory tract infection & 1 & 5 \\
Reported health concerns while on mission & 1 & 5 \\
Risks associated with earthquakes & 1 & 5 \\
Infections from patients & 1 & 5 \\
Vector-borne disease & 1 & 5 \\
Muns & 1 & 5 \\
Uncertainty about personal insurance & 7 & 5 \\
\hline & & 5 \\
\hline
\end{tabular}


coping problems and noise intolerance (three); diarrhoea (two); and fatigue (one).

\section{Suggestions for prevention}

Several participants offered suggestions for improving conditions for members of subsequent teams. These included prior training and experience, better preparation, access to a packing list, lighter clothes, more logistic support workers, provision of better personal protective equipment and alcohol hand washes, better local sharps containers, more information about earthquakes, more rest and bathing facilities and the opportunity to spend more time with other team members after finishing the mission.

\section{Discussion}

There are several limitations to this study, including incomplete information collected from all team members, the possibility of incomplete recall by participants about health concerns after the event, and perhaps a reluctance to report all concerns to investigators from within the team.

Nonetheless, it appears that CASTA team members remained largely well during the mission to Banda Aceh and in the period immediately following. The provision of safe food and water were likely to be critical in the maintenance of health, and anecdotal reports suggest that the daily debriefing sessions and mutual support among the team's members were helpful in maintaining mental well being.

Travellers to south-east Asia are at risk for a range of illnesses, notably systemic febrile illnesses, diarrhoea, skin disorders, respiratory disorders and malaria. ${ }^{1,2}$ While members of CASTA reported few serious health problems while in Aceh or after the mission was completed, many reported potential health risks, including mosquito bites and failure to complete antimalarial prophylaxis. A small number of participants did report health concerns, mainly sunburn, fatigue and headache, which may have been largely related to time spent unloading and loading equipment at the airfield in hot conditions. The low uptake of immunoglobulin and typhoid vaccine predeparture could be explained by perceived prior immunity to hepatitis $\mathrm{A}$ and typhoid by many team members. Most team members worked indoors while in Aceh, which may explain the low prevalence of sun block use.

Diarrhoea is reported by between $20 \%$ and $60 \%$ of visitors to resource-poor regions. ${ }^{3}$ In comparison, no CASTA members reported gastrointestinal illness. The preventive measures exercised, including the provision of bottled water and ration packs to all members, virtually eliminated exposures to potentially contaminated local materials. As the team experienced several aftershocks from the earthquake of up to the order of seven on the Richter scale, the high rate of concern about earthquakes is entirely understandable. Anxiety among team members was identified as a potential problem by the Australian Government, and following the mission, NSW Health's Centre for Mental Health offered counselling services to all members of the team. The team members who sustained a needle stick injury and eye splash identified no long-term effects.

In an effort to minimise occupational health and safety concerns for future missions, NSW Health has begun a review of the resources to be taken with such a team in the future. It is also reviewing screening tools, including general health and immune status, to help select appropriate team members. It may also be useful to develop a more systematic approach to facilitating the prophylactic use of antimalarials, insect repellent, long sleeved clothing and sun block, possibly through daily sign off by team members reporting compliance. Should a pool of potential team members be developed for future such missions, then systems for maintaining readiness for urgent departure through updated immunisations and training may be useful. Nationally, fact sheets with information about personal safety and health have been prepared for people travelling to and returning from tsunami-affected areas. ${ }^{4,5}$

\section{References}

1. Freedman DO, Weld LH, Kozarsky PE. Spectrum of disease and relation to place of exposure among ill returned travelers. N Engl J Med 2006; 354: 119-30. doi:10.1056/NEJMoa051331

2. Hamur A, Keystone J. Fortnightly review: evaluating fever in travellers returning from tropical countries. BMJ 1996; 312: 953-6.

3. Hill DR. The burden of illness in international travelers. $N$ Engl J Med 2006; 354: 115-7. doi:10.1056/NEJMp058292

4. Australian Government Department of Health and Ageing and Communicable Diseases Network Australia. Health pre cautions for humanitarian workers travelling to tsunamiaffected areas. Updated 2 February 2005. Available at http://www.health.gov.au/internet/wcms/publishing.nsf/ content/phd-tsunami_humanitarian.htm/\$file/ humanitarian_precautions.pdf

5. Australian Government Department of Health and Ageing and Communicable Diseases Network Australia. Health information for relief teams returning from tsunami-affected areas. Updated 2 February 2005. Available at http://www.health.gov.au/internet/wcms/publishing.nsf/ content/phd-tsunami_relief.htm/\$file/relief_teams.pdf 


\section{Cryptosporidiosis}

\section{What is cryptosporidiosis?}

Cryptosporidiosis is a diarrhoeal disease caused by the parasite, Cryptosporidium, which infects the intestine. Cryptosporidium infections have been reported in humans and in a variety of farm, pet and native animals. Although there are several species of Cryptosporidium, only two species, Cryptosporidium parvum and Cryptosporidium hominis, are thought to cause infection in humans.

Cryptosporidiosis has been notifiable to the NSW Health Department since 1996, and is a common cause of waterborne disease in NSW. Several hundred cases are usually reported in NSW each year and the number of cases tends to increase in the warmer months.

\section{What are the symptoms?}

The most common symptom of cryptosporidiosis is watery diarrhoea. Other symptoms include stomach cramps, fever, nausea, vomiting and loss of appetite. Some people with the infection have no symptoms at all.

The first signs of illness appear between 1-12 days (average 7 days) after a person becomes infected. Symptoms may come and go, but they usually disappear in less than 30 days for people with healthy immune symptoms. People with a weak immune system may have more severe symptoms that can last for many weeks.

\section{How is it spread?}

The cryptosporidiosis parasite is present in the faecal matter of infected humans and animals. The disease is passed on when the parasite is ingested. Transmission most often occurs through:

- person-to-person contact, particularly in families and among small children (for example, in child care centres)

- drinking contaminated water

- swimming in contaminated pools

- handling infected animals or their manure

- food (in rare cases)

A person is most infectious when they have diarrhoea, but the parasite may be excreted for several weeks after symptoms disappear.

\section{Who is at risk?}

People who are most likely to become infected with Cryptosporidium include:

- people in close contact with others who have cryptosporidiosis
- children who attend day care, including children in nappies

- parents of infected children

- child care workers

- swimmers who accidentally swallow swimming pool water

- people who drink untreated water (for example, from contaminated rivers, lakes, dams, wells or streams).

- travellers to developing countries

- people who work with animals

- men who have sex with men.

People with weakened immune systems are at risk for more serious disease and should see their doctor if symptoms develop.

\section{How is it prevented?}

To avoid catching cryptosporidiosis people should:

- always wash hands thoroughly with soap and water after using the toilet, handling animals or their manure, contact with faeces, changing nappies, working in the garden and before preparing food or drinks

- avoid drinking untreated water (e.g. from rivers, lakes, streams or dams - boiling water from these sources for one minute will kill germs, including cryptosporidiosis)

- avoid swallowing water when swimming

- avoid swimming in natural waters (e.g. rivers, creeks, dams, surf) within a week after heavy rain events

- in developing countries avoid food or drinks that may be contaminated (e.g. raw vegetables, tap water or ice made from tap water)

To avoid spreading cryptosporidiosis, people with cryptosporidiosis should:

- not swim for at least two weeks after the diarrhoea has stopped

- not share towels or linen for at least 2 weeks after the diarrhoea has stopped

- keep small children who have diarrhoea home from school, preschool, childcare or playgroup until $24 \mathrm{~h}$ after the diarrhoea has completely stopped

- do not handle food for at least $48 \mathrm{~h}$ after the diarrhoea has stopped

\section{How is it diagnosed?}

If you have diarrhoea the only way to tell if it is cryptosporidiosis is by going to a doctor and having a stool specimen taken. 


\section{How is it treated?}

There is no specific treatment for cryptosporidiosis. Drink plenty of fluids to avoid dehydration.

\section{What is the public health response?}

Laboratories are required to notify cases of cryptosporidiosis to the local Public Health Unit under the Public Health Act, 1991. Public Health Units investigate cases, and review possible sources of infection to prevent further spread.

\section{For more information}

Please contact your doctor, local public health unit or community health centre.

\section{NSW丹HEALTH}

\section{BUG BREAKFAST IN THE BULLETIN}

\section{Bug Breakfast* in the Bulletin: refugee health}

\author{
Katina Kardamanidis ${ }^{\mathrm{A}, \mathrm{D}}$, Mitchell M. Smith ${ }^{\mathrm{B}}$ and \\ Sanjyot Vagholkar ${ }^{\mathrm{C}}$

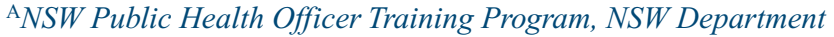 \\ of Health. \\ ${ }^{\mathrm{B}} \mathrm{NSW}$ Refugee Health Service. \\ ${ }^{\mathrm{C}}$ General Practice Unit, Fairfield Hospital. \\ ${ }^{\mathrm{D}}$ Corresponding author. Email: \\ katina.kardamanidis@doh.health.nsw.gov.au
}

Refugees are people living outside of their country of nationality because of a well-founded fear of persecution for reasons of race, religion, nationality, membership of a certain social group or political opinion. ${ }^{1}$ Asylum seekers are people who have applied for recognition as refugees and are awaiting a decision on their application. ${ }^{2}$ If their application is successful they receive refugee status.

\section{Australia's humanitarian program}

There are two components to Australia's humanitarian migration program: the first and largest component is the resettlement in Australia of people who have been given refugee status elsewhere ('offshore resettlement' of refugees); the second component is for people applying for refugee status while already in Australia ('onshore protection' of asylum seekers). ${ }^{3}$ Asylum seekers are either 'authorised arrivals' who enter Australia on a valid visa such as a visitor's or student visa or 'unauthorised arrivals' who enter Australia by boat or plane without a visa. ${ }^{4}$ Unauthorised arrivals are detained in various immigration detention centres across Australia while their refugee claims are processed.

\section{Screening for infectious diseases in NSW}

Asylum seekers who arrive in an unauthorised manner receive health screening in the detention centres. Authorised asylum seekers, who are generally allowed to remain in the community while their applications are processed, may have received health screening in their country of origin as part of their visa requirements, and will undergo further checks.

Refugees, on which the remainder of this article will focus, have to undergo the same health checks as other migrants before receiving humanitarian visas to travel to Australia, including tests for tuberculosis and, depending on age, HIV. Since mid-2005, a proportion also undergo health checks immediately predeparture, organised by the Australian Government. These include an assessment of their fitness to fly and rapid malaria testing when appropriate. They are given antiparasitic treatment and, for those under 30 years of age, measles, mumps and rubella vaccination.

Refugees normally arrive in Australia in family groups. Health screening processes after arrival differ between and within the States and Territories. In NSW, screening varies depending on where in NSW the refugees are settled by the Department of Immigration and Citizenship. The NSW Refugee Health Service, funded by NSW Health,

*Bug Breakfast is the name given to a monthly series of hour-long seminars on communicable diseases delivered by the NSW Department of Health's Division of Population Health. 
runs assessment clinics in Sydney, where the majority of refugees settle. The Children's Hospital Westmead has also established a dedicated clinic. Area Health Services have set up clinics for assessing refugees settling in Newcastle and Coffs Harbour. These people are offered a link to mainstream health services such as General Practitioners (GPs) and dental clinics or to the specialised NSW Service for the Treatment and Rehabilitation of Torture and Trauma Survivors.

Some refugees arriving in Australia have infectious diseases, including malaria, schistosomiasis, hepatitis B and Helicobacter pylori. Sometimes unusual tropical diseases are diagnosed, such as Chigoe flea in refugees from a Tanzanian camp. ${ }^{5}$ A number of refugees are under-immunised, for example for measles and rubella. ${ }^{6}$

\section{Large arrival: Burundian charter flight}

In early 2005, the Australian Government arranged several charter flights to bring large groups of refugees to Australia. In February, a group of 300 Burundian refugees arrived, of which 30 came to Fairfield in Sydney. These people had lived in Tanzanian refugee camps for up to 10 years. The General Practice Unit at Fairfield Hospital was asked to provide screening and immunisation. The refugees were screened for Hepatitis B, malaria, schistosomiasis, strongyloides, hookworm and Giardia, and where necessary, they were vaccinated.

The challenges posed by the newly arrived refugees were: ascertaining past medical history; collecting blood and stool specimens; and explaining test results. With the cultural and language barrier, the availability of an interpreter was critical. Organising follow-up tests or treatment was difficult as it was not easy for the refugees to get to the hospital in a city environment that was completely new to them. They also had to negotiate the social security system, enrol their children in school, start to learn English and perhaps seek a job. Consequently, for recently arrived refugees, their health may not always be the first priority.

\section{Filling the gaps}

For resettled refugees medical care is relatively good but there are still some important concerns such as: difficulties in completing immunisation schedules where immunisation histories are unclear and where refugees have passed the age at which certain vaccines are normally given; the provision of certain medications (e.g. Praziquantel for schistosomiasis) that are not covered by the Pharmaceutical Benefits Scheme; and the debate across different jurisdictions with regards to the degree of additional tuberculosis screening that may be warranted.

A positive initiative is the development of protocols and guidelines for the screening and treatment of resettled refugees. Recently, a new Medicare item number was introduced to remunerate GPs who undertake health assessments for newly arrived refugees. These and other issues are under discussion through a national MultiJurisdictional Working Group on refugee health issues.

For asylum seekers, medical care in detention centres as well as in the community has been criticised for not meeting adequate standards. ${ }^{4,7-9}$ Recent attention has been given to those asylum seekers living in the community without access to Medicare, with discussions taking place nationally about how to facilitate access to primary health services and hospital care.

\section{References}

1. United Nations High Commissioner for Refugees. Article 1a, 1951 convention relating to the status of refugees. Available at http://www.unhcr.org/protect/3c0762ea4.html. Accessed 2 January 2007.

2. United Nations High Commissioner for Refugees. Definitions and obligations. Available at http://www.unhcr.org.au/basicdef.shtml\#top. Accessed 2 January 2007.

3. Department of Immigration and Citizenship. Migrating as a refugee or humanitarian entrant. Available at http://www.immi.gov.au/refugee/migrating/index.htm. Accessed 2 January 2007.

4. Correa-Velez I, Gifford S, Bice S. Australian health policy on access to medical care for refugees and asylum seekers. Aust N Z Health Policy 2005; 2: 23.

5. Swaminathan A, Gosbell I, Zwar N, Douglas M. Tungiasis in recently arrived African refugees. Med J Aust 2005; 183(1): 51.

6. Population Health Division. The health of the people of New South Wales: report of the Chief Health Officer, 2004. Sydney: NSW Department of Health, 2004.

7. Australian Human Rights and Equal Opportunity Commission (HREOC). A report on visits to immigration detention facilities by the human rights commissioner, 2001. Available at http://www.humanrights.gov.au/human_rights/ide/index.html. Accessed 2 January 2007.

8. Public Health Association Australia. Asylum seekers: mandatory detention. Available at http://www.phaa.net.au/policy/ASYLUMSEEKERSJF.htm. Accessed 2 January 2007.

9. Public Health Association Australia. Refugee health. Available at http://www.phaa.net.au/policy/Refugee $\% 20$ health\%20F.htm. Accessed 2 January 2007. 


\section{Communicable Diseases Report, New South Wales, for November and December 2006}

\section{Communicable Diseases Branch, NSW Department of Health}

For updated information, including data and facts on specific diseases, visit www.health.nsw.gov.au and click on Infectious Diseases.

\section{Trends}

Tables 3 and 4 and Fig. 4 show reports of communicable diseases received through to the end of November and December 2006 in NSW. There was an increase in notifications of cryptosporidiosis in November (see http://www.health.nsw.gov.au/data/diseases/cryptosporidiosis.html) largely from the New England and mid western regions of the state.

\section{Three cholera cases linked to eating raw imported whitebait}

In late November an infectious disease physician with Sydney South West Area Health Service reported that Vibrio bacteria had been identified in the stools of three women with diarrhoea. Subsequent testing of the bacteria confirmed that it was Vibrio cholerae O1 Ogawa El Tor, which is able to produce cholera toxin.

Investigation identified that the only common exposure amongst the women was eating raw whitebait while preparing it for cooking at home. A subsequent trace back investigation by the NSW Food Authority revealed that a single supplier from Indonesia had imported the implicated food, and a media release was issued urging people to avoid eating raw whitebait. Active surveillance was instituted but no further cases of cholera were discovered. The three women subsequently recovered.

\section{Outbreak of Salmonella Montevideo infections}

An increase in the number of notifications of patients with Salmonella Montevideo infection was identified in November (16 compared with a mean of two for November during each of the previous 5 years). The patients resided throughout the Sydney metropolitan area and the Hunter New England Area. No clustering has been identified among cases to date. Public health units have been asked to interview patients using a standard questionnaire in an attempt to identify common exposures.

\section{Two blue families: unintentional ingestion of sodium nitrate}

In September, a Chinese couple presented to a Sydney South West hospital with vomiting, drowsiness and cyanosis. Two weeks later three members of a Vietnamese family presented to the same hospital with severe vomiting and cyanosis. A fourth member of the second group also became ill but spontaneously recovered without seeking medical intervention. In both instances clinicians diagnosed methaemoglobinaemia. Several of the people required treatment with the antidote methylene blue. All made complete recoveries.

Methaemoglobinaemia is a rare disorder in which the iron atom of haemoglobin oxidises from the ferrous state to the ferric state, leading to reduced oxygen-carrying capacity and cyanosis. Other symptoms and signs include headache, nausea, vomiting, lethargy, shortness of breath, tachycardia and decreased levels of consciousness. Methaemoglobinaemia may be caused by a variety of chemicals including antimalarial and anaesthetic drugs and nitrites. Rarely it may be caused by genetic defects in red blood cells. ${ }^{1}$ The few documented clusters of cases of methaemoglobinaemia recorded in the literature have resulted from misuse of nitrites in food preparation..$^{2-4}$

In response to these reports, public health units were asked to alert emergency departments to report other possible cases. None were identified. In collaboration with the NSW Food Authority and Sydney South West Public Health Unit, epidemiological investigations were carried out to determine a possible link between the two clusters. Interviews with families revealed that in both circumstances the Goldfish brand Nutre Powder had been used in the preparation of food which had been consumed just minutes before the onset of symptoms. In the first cluster, the cases had eaten Nutre Powder used in making rice cakes; in the second cluster, cases had eaten Nutre Powder added to a barbequed pork dish.

The Nutre Powder was purchased from separate Asian grocery stores in the Sydney South West Area. It did not contain any ingredient listing, warnings or instructions for use. Leftover Nutre Powder was collected from the first family and submitted for laboratory testing. Results indicated that this powder was $100 \%$ sodium nitrite. It had 
been imported from China through Victoria from where it was distributed to retailers in Victoria, New South Wales and South Australia. Interviews with various retailers and patrons at various Chinese grocery shops revealed uncertainty about its actual purpose, which ranged from tooth powder to foot powder to food flavour enhancer to meat preservative.

Victorian health authorities initiated a national recall of this product and NSW Health issued a media release advising the public not to consume Goldfish brand Nutre Powder. Ethnic radio and newspaper media were specifically used to target Asian populations. These events highlight the importance of correct labelling and appropriate warnings on packages sold in grocery stores.

\section{Recent increase in haemolytic uraemic syndrome cases}

From November to December 2006 NSW Health received eight notifications of haemolytic uraemic syndrome (HUS). All eight cases had a history of diarrhoeal illness before the onset of HUS, and in three, Shiga toxigenic Escherichia coli (STEC) were detected in stool specimens. Of these, two were identified as E. coli $\mathrm{O} 157$ and one as E. coli $\mathrm{O} 55$. The age of cases ranged from 1 to 27 years (median 6 years) and $56 \%$ were male. There was no geographical clustering of cases.

During November to December 2005, a similar increase was seen with seven HUS cases reported. The public health unit found no common links among the cases. In each of the five years from 2000 to 2004, an average of two HUS cases were reported for the November to December period.

HUS is a severe, sometimes fatal, condition characterised by kidney failure, bleeding and anaemia that more commonly occurs in children. Symptoms of HUS may include bruising or a rash of fine red spots, reduced urination and reduced consciousness. ${ }^{5}$ About $90 \%$ of HUS cases are associated with diarrhoea, and of these, most (at least in the United States) are caused by STEC infections. ${ }^{6}$

Symptoms of STEC infection commonly include diarrhoea that may be bloody, abdominal cramps, nausea and vomiting lasting 5 to 10 days. More commonly recognised strains of STEC include E. coli $\mathrm{O} 111$ and E. coli O157. In about $8 \%$ of cases, infection can lead to HUS. ${ }^{5}$

In many countries cattle are a common reservoir of $\mathrm{STEC}^{7}$ and ingestion of food contaminated with infected cattle faeces (e.g. undercooked burger patties, unwashed salad vegetables, and unpasteurised milk or milk products) is the most common mode of transmission. ${ }^{8}$ STEC infections have also been documented from drinking or swimming in contaminated water. ${ }^{9}$
In light of the recent increase in HUS case notifications, NSW Health initiated enhanced surveillance for STEC infections and HUS. Public health staff alerted paediatric renal units and pathology laboratories throughout the state of the increase, and requested STEC testing on all undiagnosed bloody stools. The eight HUS cases were interviewed for possible food and environmental risks but no common links were identified. STEC infection and HUS can be prevented by: thorough hand washing; safe handling, cooking and storage of food; and by avoiding unpasteurised products.

\section{Influenza surveillance for NSW in 2006}

The 2006 influenza season for NSW was mild. Influenza activity peaked in late August. Two influenza A outbreaks were identified, one in an aged care facility and one in a school. Here we provide an overview of enhanced influenza surveillance program in NSW during the 2006 season.

\section{Background}

Influenza is highly contagious and mainly caused by influenza viruses A and B. The virus is usually spread from person to person through droplets when an infected person coughs or sneezes. People with influenza can help prevent its spread by resting at home while sick, covering their nose and mouth when they cough or sneeze and regularly washing their hands with soap and running water. Symptoms include a sudden onset of fever, headache, muscle and joint pain, tiredness, sore throat, cough and runny or stuffy nose. Symptoms usually appear within 1 to 3 days of being infected, and a person is usually contagious for 3 to 4 days. Up to $30 \%$ of the community could catch influenza each year. Influenza can be prevented by annual vaccination. ${ }^{10}$ Vaccination is available from general practitioners. In recent years in NSW, the influenza season has peaked any time from July to September.

\section{Methods}

The NSW Influenza Surveillance Program runs from May to October each year. Data sources for 2006 included reports of:

- Influenza like illness (ILI) from 30 emergency departments across the greater Sydney area (Auburn, Bankstown, Blacktown, Bowral, Camden, Campbelltown, Canterbury, Children's Hospital at Westmead, Concord, Fairfield, Gosford, Hornsby, Liverpool, Manly, Mona Vale, Mount Druitt, Prince of Wales, Royal North Shore, Royal Prince Alfred, Ryde, Wollongong, Shellharbour, Shoalhaven, St George, St Vincent's, Sutherland, Sydney Hospital, Sydney Children's, Westmead and Wyong hospitals). Rates of ILI less than 2.0/1000 presentations are considered 'low', 2.0 to $3.9 / 1000$ consultations 'moderate', 4.0 to $5.9 / 1000$ consultations 'high' and greater than 6.0/1000 consultations 'very high'. 


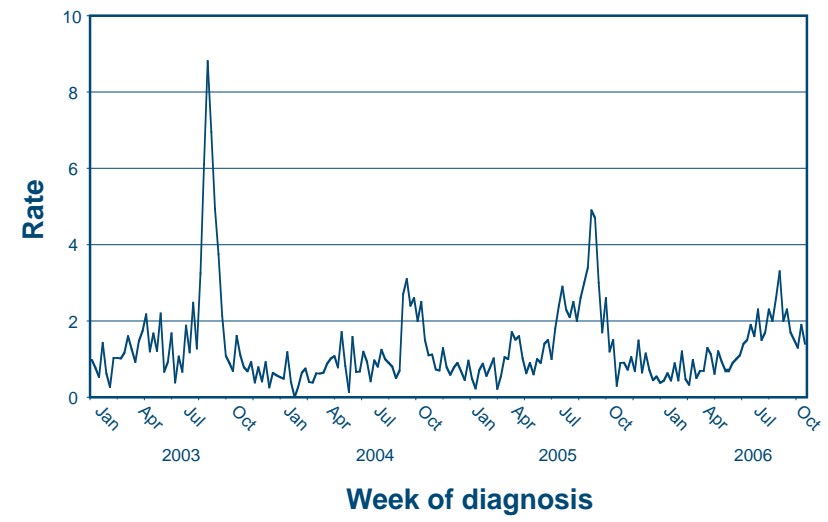

Fig. 1. Rate of influenza like illness per 1000 presentations to participating emergency departments, New South Wales, 1 January 2003 to 6 October 2006

- Laboratory diagnoses of respiratory viral infections by six major public laboratories: South East Area Laboratory Service (SEALS), Institute of Clinical Pathology and Medical Research (ICPMR), South West Area Pathology Service (SWAPS), Pacific Laboratory Medicine Service (PaLMS), Hunter Area Pathology Service (HAPS) and Children's Hospital at Westmead (CHW). All six laboratories provided virology reports, and three (SEALS, ICPMR and HAPS) also provided serology reports.

- National and international influenza activity from the World Health Organization Collaborating Centre for Reference and Research on Influenza, Melbourne. ${ }^{11}$

The surveillance program monitors general trends in influenza rather than the total number of people who are infected each year.

\section{Results}

\section{Emergency Department surveillance}

For the majority of the 2006 influenza season, ILI rates from emergency departments were low. The highest reported rate (3.3 per 1000 presentations) occurred in late

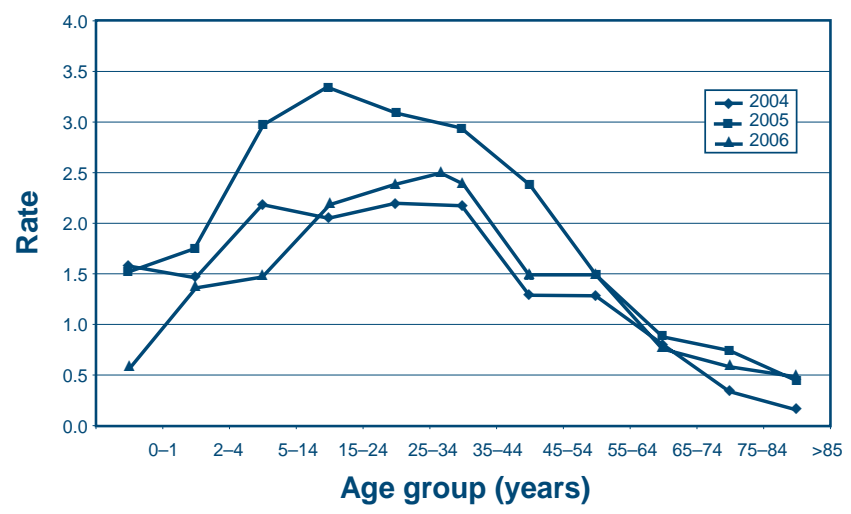

Fig. 2. Rate of influenza like illness per 1000 presentations to participating emergency departments, by age group, New South Wales, 2004 to 2006

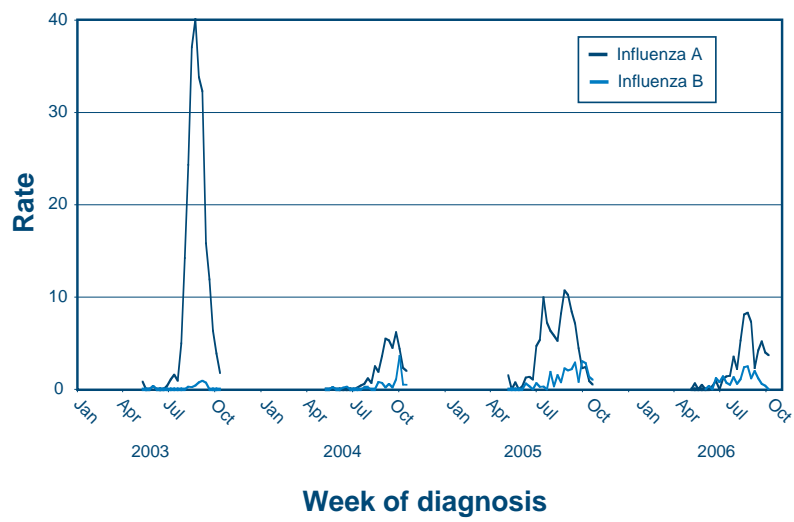

Fig. 3. Rate of influenza virus detection by direct immunofluorescence per 100 samples for six major public laboratories, New South Wales, 1 May 2003 to 6 October 2006

August. The mean rate of ILI presentations was 1.7 per 1000 presentations (range $0.7-3.3$ ). In 2005, the mean rate was 2.3 per 1000 presentations (range $0.3-4.9$ ). In total, $40 \%$ of cases diagnosed with an ILI were aged 15-34 years, $12 \%$ were children under the age of 5 years. Overall, $6 \%$ of ILI cases presenting to emergency departments were admitted to hospital (Figs 1 and 2).

\section{Laboratory surveillance}

Virology: For the 2006 surveillance period, 12356 respiratory samples were tested for influenza and other respiratory viruses. Of these 268 (2\%) were positive for influenza A (by direct immunofluorescence (DIF), polymerase chain reaction (PCR) or culture). The highest rate reported (8.1 per 100 samples, by DIF) was for the week ending 20 August. The mean DIF rate was 2.6 per 100 samples. The mean DIF rate for 2005 was 3.0 per 100 samples. The majority of positive influenza samples in 2006 came from children less than 5 years (46\%) (Fig. 3; Table 1).

Of all samples, 119 (1\%) tested positive for influenza B (by DIF, PCR or culture). The highest rate (DIF rate 2.5 per 100 samples) was recorded week ending 27 August. The mean DIF rate was 0.8 per 100 samples, which was similar to that reported in 2005 (DIF rate 1.0 per 100 samples) (Fig. 3; Table 1).

Serology: For the 2006 surveillance period the six participating laboratories tested 2720 serum samples for evidence of infection with influenza (characterised by seroconversion or rise in $\mathrm{IgG}$ level or high single titre to influenza virus or RSV). Of these, 77 samples (2.8\%) had a high serological titre and $28(1 \%)$ had a 4 -fold rise in titre for influenza A. The highest rate (9.7 per 100 samples) was reported in the week ending 14 July. The mean rate in 2006 (3.9 per 100 samples) was lower than in 2005 (6.0 per 100 samples) (Table 2).

Sixty samples $(2.2 \%)$ had a high serological titre and one $(<0.1 \%)$ had a 4 -fold rise in titre for influenza B. There 
Table 1. Results of 7202 respiratory specimens tested by direct immunofluoescence, and week of peak activity, for six major laboratories, New South Wales, 29 April to 6 October 2006

\begin{tabular}{lrrlrc}
\hline Virus & Peak number positive & \multicolumn{2}{c}{ Week-ending for } & \multicolumn{2}{c}{ Total number positive } \\
& $n$ & $\%$ & peak number positive & $n$ & $\%$ \\
\hline Influenza B & 11 & 16 & 25 August & 67 & 1 \\
Adenovirus & 8 & 9 & 8 September & 86 & 1 \\
Para influenza 1 & 5 & 17 & 23 June & 30 & 0.4 \\
Para influenza 2 & 1 & 17 & 26 May & 6 & 0.08 \\
Para influenza 3 & 15 & 13 & 22 September & 113 & 2 \\
RSV & 190 & 12 & 14 July & 1628 & 23 \\
Rhinovirus & \multicolumn{7}{c}{ Number too small to judge } & 3 & 0.04 \\
\hline
\end{tabular}

were two small peaks identified throughout the season, a rate of 6.0 per 100 samples for the week ending 19 May and a rate of 5.6 per 100 samples for the week ending 26 July. The mean rate for 2006 ( 2.2 per 100 samples) was higher than in 2005 (1.5 per 100 samples) (Table 2).

\section{Outbreaks}

Two influenza outbreaks were reported in 2006. The first was in an aged care facility within the Greater Western Area Health Service. In total, 7 of 17 residents and one staff member reported ILI symptoms. Nose and throat swabs were taken from six residents and four of these were positive for influenza A. The second outbreak was reported from a high school in the Hunter/New England Area. More than 120 students presented with ILI symptoms and six cases were admitted to the local hospital with pneumonia. Nose and throat swabs were taken from several students of which six were positive for influenza A by PCR. Eight blood cultures were taken of which two grew Streptococcus pneumoniae (serotype 1). For both outbreaks a range of control measures were implemented following the national guidelines. ${ }^{12}$

\section{National and international situation}

Up to 26 October 2006, Queensland had the highest number of influenza notifications (1175) followed by NSW (476), Victoria (388) and Western Australia (189). ${ }^{11}$
The World Health Organization Collaborating Centre for Reference and Research on Influenza in Melbourne had analysed 562 influenza strains supplied by laboratories in Australia as at 20 October 2006. Of these, 22 were A (H1) strains, 320 were A (H3) strains and 220 were B strains. The majority of B strains (206) were Malaysia-like while the remainder (14) were Shanghai-like. Of the 2411 laboratory-confirmed cases reported in 2006, 1667 (69.1\%) were type A, $656(27.2 \%)$ were type B, 31 cases $(1.3 \%)$ were typed as $\mathrm{A} \& \mathrm{~B}$ and for 57 cases (2.4\%) type was not reported. ${ }^{13}$

The World Health Organization reports that during the period February to September 2006, influenza A (H1N1), A (H3N2) and B viruses circulated in many parts of the world. ${ }^{12}$

- Influenza A (H1N1) viruses were associated with outbreaks in Africa (Egypt), the Americas (Brazil), Asia (Hong Kong SAR, China, Japan and Thailand) and Europe (Spain). The majority of isolates were similar to A/New Caledonia/20/99.

- Influenza A (H3N2) viruses were also associated with widespread outbreaks in several countries. Most recent isolates were similar to the vaccine viruses

A/Wisconsin/67/2005 and A/Hiroshima/52/2005.

Table 2. Results of 2720 respiratory specimens tested by serology, and week of peak activity, for six major laboratories, New South Wales, 29 April to 6 October 2006

\begin{tabular}{|c|c|c|c|c|c|}
\hline \multirow[t]{2}{*}{ Virus } & \multicolumn{2}{|c|}{ Peak number positive } & \multirow{2}{*}{$\begin{array}{l}\text { Week-ending for } \\
\text { peak number positive }\end{array}$} & \multicolumn{2}{|c|}{ Total number positive } \\
\hline & $n$ & $\%$ & & $n$ & $\%$ \\
\hline Influenza A & 14 & 13 & 21 July & 105 & 4 \\
\hline Influenza B & 5 & 8 & 18 August & 61 & 2 \\
\hline Adenovirus & 2 & 20 & 8 September & 10 & 0.4 \\
\hline Para influenza 1 & 5 & 33 & 14 July & 15 & 0.6 \\
\hline Para influenza 2 & 4 & 50 & 4 August & 8 & 0.3 \\
\hline Para influenza 3 & \multicolumn{3}{|c|}{ Number too small to judge } & 3 & 0.1 \\
\hline RSV & \multicolumn{3}{|c|}{ Number too small to judge } & 7 & 0.3 \\
\hline Rhinovirus & \multicolumn{3}{|c|}{ Number too small to judge } & 0 & 0 \\
\hline
\end{tabular}


- Influenza B outbreaks were reported in many countries in Asia and Europe, and in Egypt and the United States. The majority of recent isolates were similar to B/Malaysia/2506/2004 (B/Victoria/2/87 lineage).

\section{7 vaccine}

The composition of the influenza vaccine is determined annually by the World Health Organization and the Australian Vaccine Committee based on current influenza circulating viruses. The recommended ${ }^{13}$ composition of influenza vaccine (Southern Hemisphere) for 2007 is:

- A/New Caledonia/20/99

- $\mathrm{A} /$ Wisconsin/67/2005

- B/Malaysia/2506/2004.

Influenza surveillance report prepared by Communicable Diseases Branch, NSW Health, in collaboration with: NSW Emergency Department Data Collection (HOIST), and NSW Public Health Real-time Emergency Department Surveillance System (Centre for Epidemiology and Research, NSW Department of Health), South East Area Laboratory Service (SEALS), Institute of Clinical Pathology and Medical Research (ICPMR), South West Area Pathology Service (SWAPS), Pacific Laboratory Services (PaLMS), Hunter Area Pathology Service (HAPS), New Children's Hospital (CHW). Enquiries to Robin Gilmour, ph. 029424 5875, email: rgilm@doh.health.nsw.gov.au

\section{References}

1. Rehman HU. Methemoglobinemia West J Med 2001; 175(3): 193-6. doi:10.1136/ewjm.175.3.193

2. Askew GL, Finelli L, Genese CA, Sorhage FE, Sosin DM, Spitalny KC. Boilerbaisse: an outbreak of methemoglobinemia in New Jersey in 1992. Pediatrics 1994; 94(3): 381-4.

3. Kennedy N, Smith CP, McWhinney P. Faulty sausage production causing methaemoglobinaemia. Arch Dis Child 1997; 76(4): 367-8.
4. Centres for Disease Control and Prevention (CDC) Methemoglobinemia following unintentional ingestion of sodium nitrite-New York, 2002 MMWR Morb Mortal Wkly Rep 2002; 51(29): 639-42.

5. Heymann DL, editor. Control of Communicable Diseases Manual, 18th edn. Washington DC: American Public Health Association, 2004.

6. http://www.cdc.gov/ncidod/eid/vol3no3/mahon.htm. Accessed 3 April 2007.

7. Hussein HS, Bollinger LM. Prevalence of Shiga toxinproducing Escherichia coli in beef cattle. J Food Prot 2005; 68(10): 2224-41.

8. Bell BP, Goldoft M, Griffin PM, Davis MA, Gordon DC, Tarr PI et al. A multistate outbreak of Escherichia coli O157:H7-associated bloody diarrhea and hemolytic uremic syndrome from hamburgers. The Washington experience. JAMA 1994; 272(17): 1349-53. doi:10.1001/jama.272.17.1349

9. Keene WE, McAnulty JM, Hoesly FC, Williams LP Jr, Hedberg K, Oxman GL et al. A swimming-associated outbreak of hemorrhagic colitis caused by Escherichia coli $\mathrm{O} 157: \mathrm{H} 7$ and Shigella sonnei. N Engl J Med 1994; 331(9): 579-84. doi:10.1056/NEJM199409013310904

10. National Health \& Medical Research Council. The Australian Immunisation Handbook, 8th edn. Canberra: AGPS, 2003.

11. Communicable Diseases Network Australia. Guidelines for the prevention and control of influenza outbreaks in residential care facilities. Australian Government Department of Health and Ageing, 2005. http://www.health.gov.au/internet/wcms/ publishing.nsf/content/cda-pubs-other-flu_guidel.htm. Accessed 3 April 2007.

12. WHO Collaborating Centre for Reference and Research on Influenza, Parkville Victoria. http://www.influenzacentre.org. Accessed 3 April 2007.

13. WHO Global Influenza Surveillance Network, Geneva. http://www.who.int/csr/disease/influenza/surveillance/en/ Accessed 3 April 2007. 
Fig. 4. Reports of selected communicable diseases, NSW, Jan 2001 to December 2006, by month of onset. Preliminary data: case counts in recent months may increase because of reporting delays. Laboratory-confirmed cases only, except for measles, meningococcal disease and pertussis.

$\mathrm{BFV}=$ Barmah Forest virus infections, RRV $=$ Ross River virus infections, Laboratory Conf $=$ laboratory confirmed, Men

$\mathrm{Gp} C$ and $\mathrm{Gp} B=$ meningococcal disease due to serogroup $C$ and serogroup $B$ infection, other/unk = other or

unknown serogroups. N.B.: multiple series in graphs are stacked, except gastroenteritis outbreaks. NB. Outbreaks are more likely to be reported by nursing homes \& hospitals than by other institutions

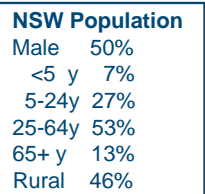
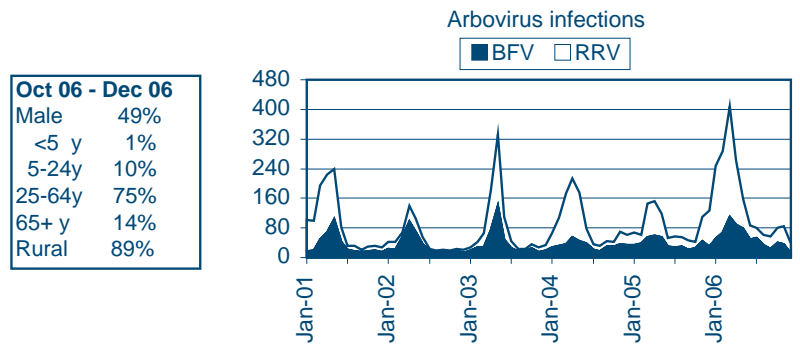

Cryptosporidiosis

\begin{tabular}{|cc|}
\hline Oct 06 & - Dec 06 \\
Male & $49 \%$ \\
$<5$ y & $40 \%$ \\
$5-24 y$ & $37 \%$ \\
$25-64 y$ & $21 \%$ \\
$65+y$ & $2 \%$ \\
Rural & $70 \%$ \\
\hline
\end{tabular}

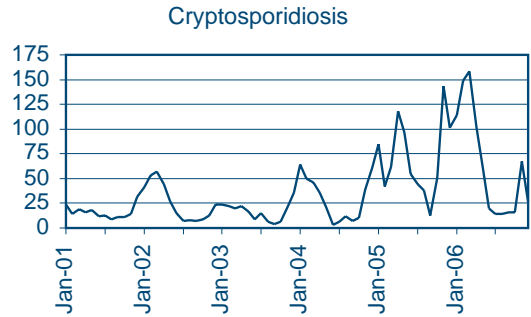

Gastroenteritis outbreaks in institutions

\begin{tabular}{|lr|}
\hline Oct 06 - Dec 06 \\
All outbreaks & 60 \\
Nursing homes & 32 \\
Hospitals & 14 \\
Child care & 11 \\
Schools & 0 \\
Other & 3 \\
\hline
\end{tabular}

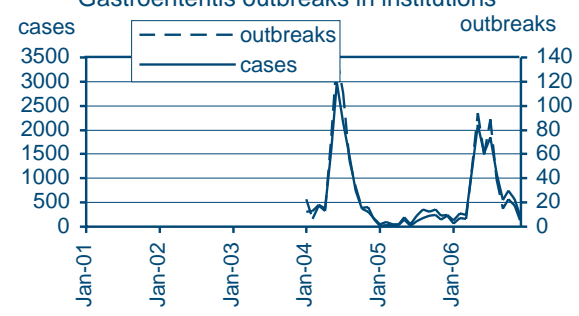

Gonorrhoea

\begin{tabular}{|lc|}
\hline Oct 06 & - Dec 06 \\
Male & $87 \%$ \\
$<5$ y & $0 \%$ \\
$5-24 y$ & $18 \%$ \\
$25-64 y$ & $81 \%$ \\
$65+y$ & $1 \%$ \\
Rural & $13 \%$ \\
\hline
\end{tabular}

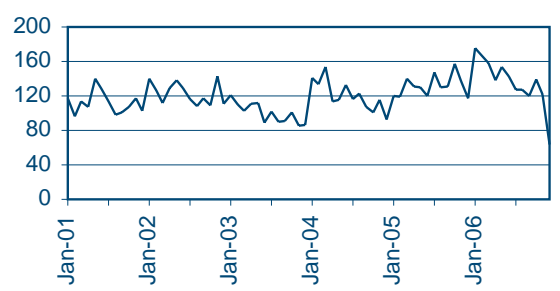

Hepatitis A

\begin{tabular}{|cc|}
\hline Oct 06 & - Dec 06 \\
Male & $30 \%$ \\
$<5$ y & $0 \%$ \\
$5-24 y$ & $30 \%$ \\
$25-64 y$ & $50 \%$ \\
$65+y$ & $20 \%$ \\
Rural & $10 \%$ \\
\hline
\end{tabular}
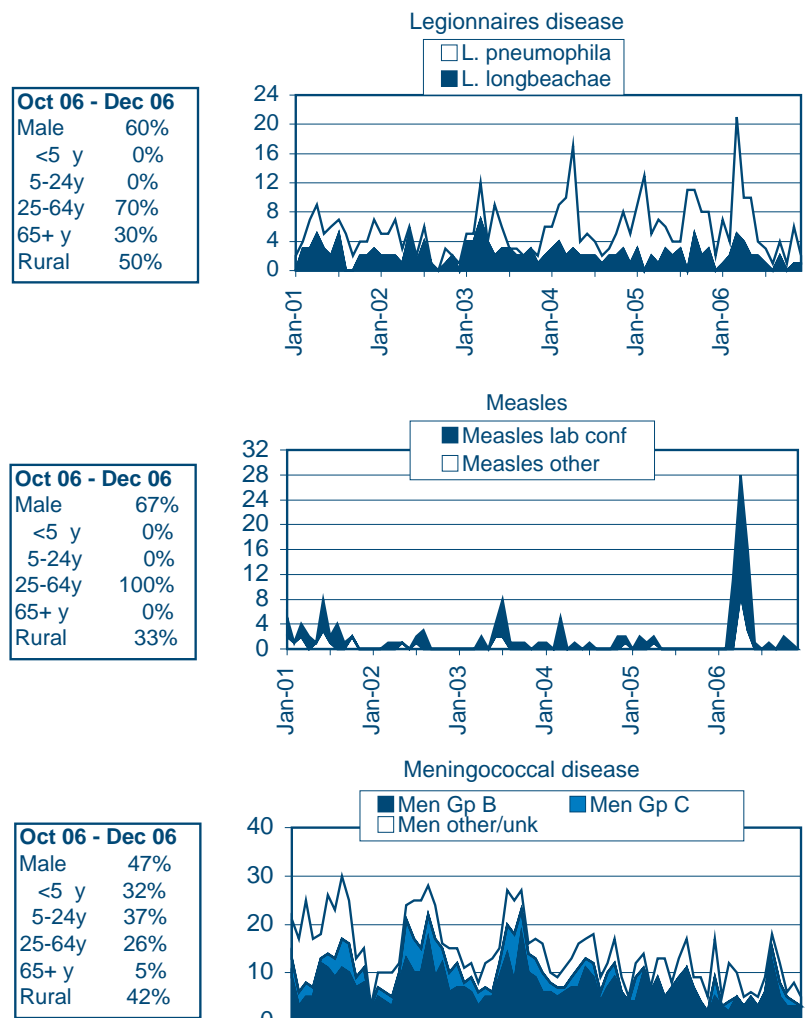

Measles

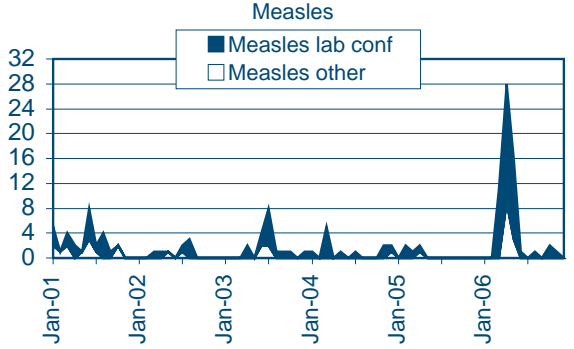

Meningococcal disease

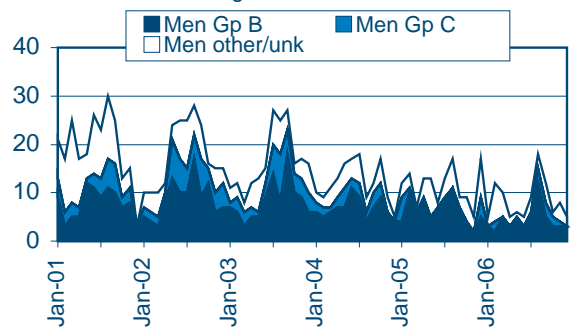

Oct 06 - Dec 06 Male $43 \%$

$<5$ y $9 \%$ $5-24$ y $10 \%$ $25-64 y \quad 63 \%$ $65+y \quad 18 \%$ Rural $49 \%$

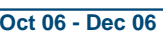

Male $\quad 49 \%$

$<5$ y $24 \%$

$5-24 y \quad 29 \%$

$25-64 y \quad 37 \%$

$65+y \quad 10 \%$

Rural $42 \%$
Pertussis
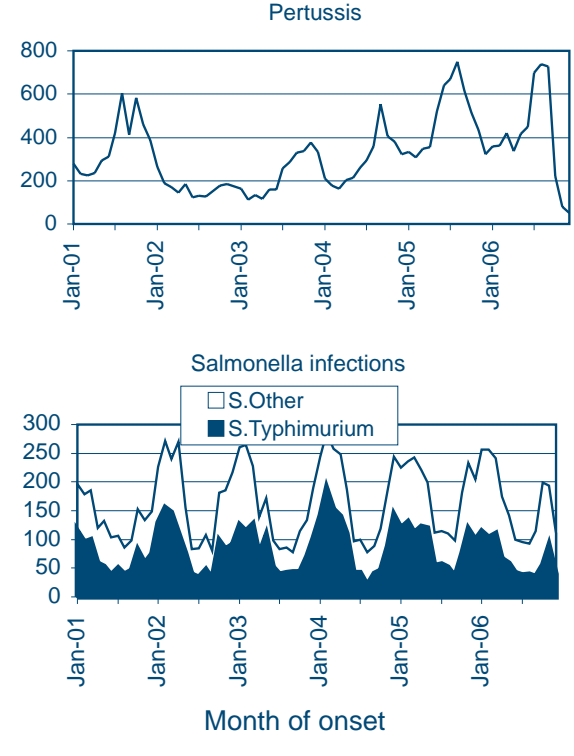
Table 3. Reports of notifiable conditions received in November 2006 by area health services

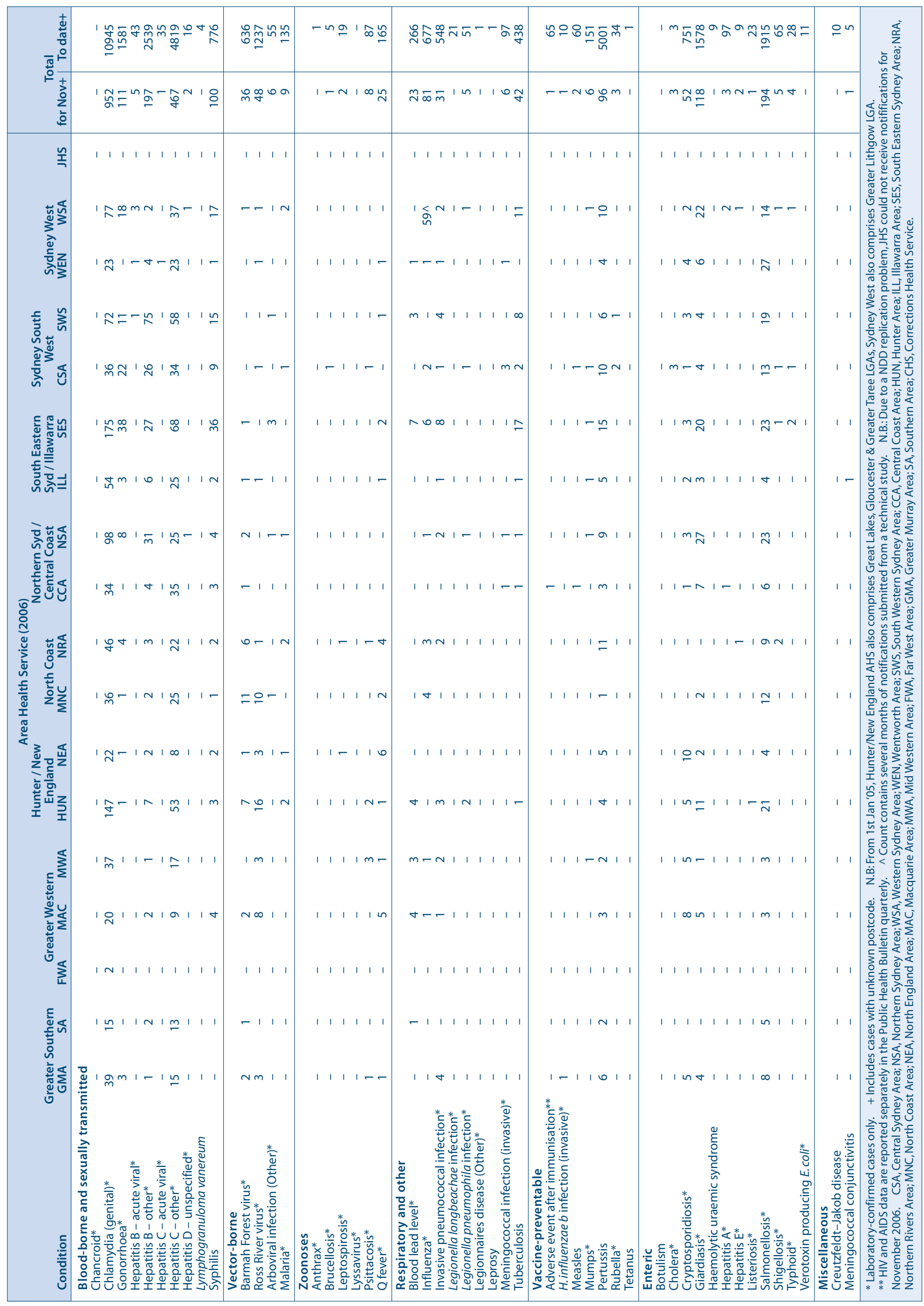


Table 4. Reports of notifiable conditions received in December 2006 by area health services

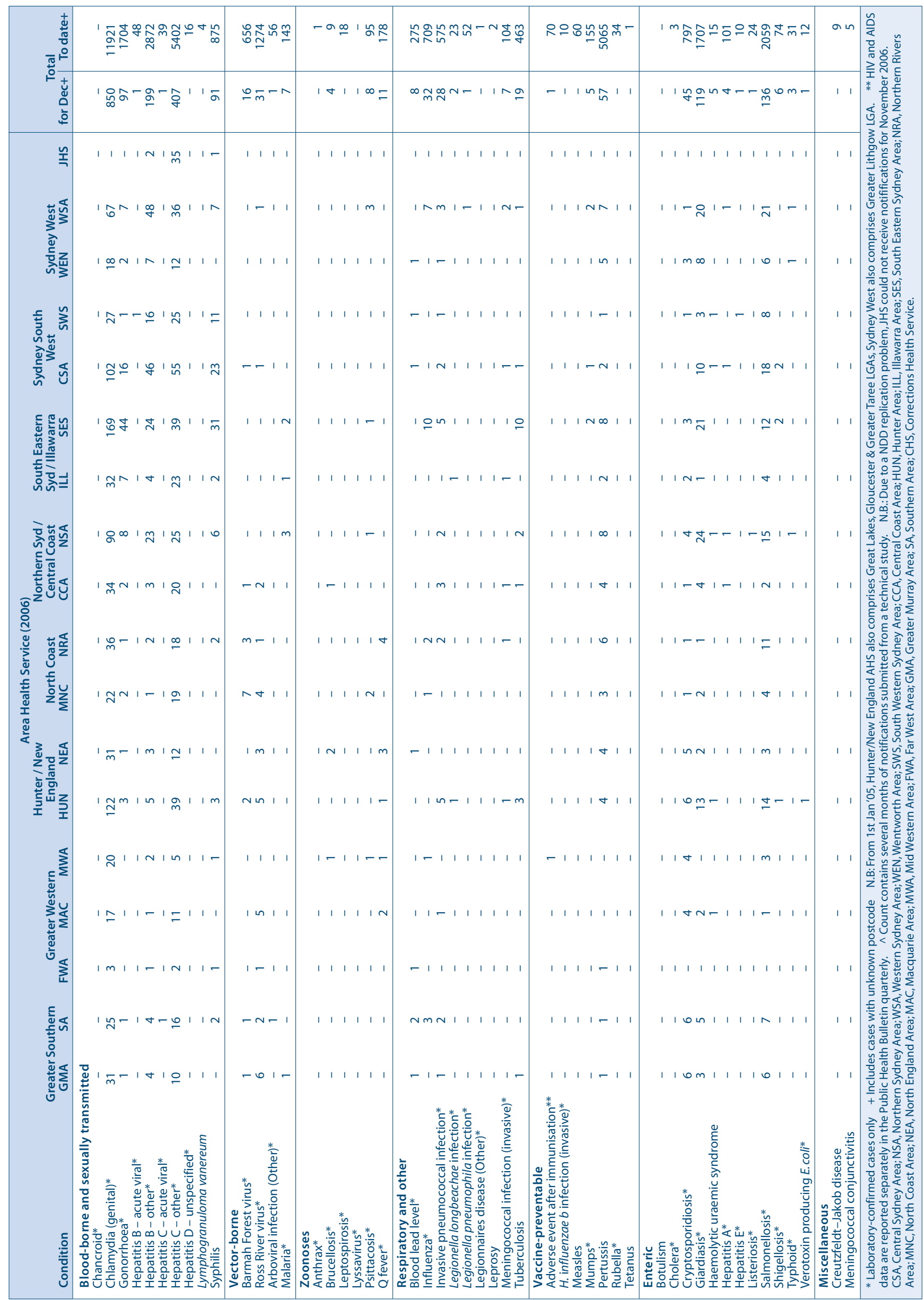




\section{Contents}

\section{Special issue: public health workforce}

1 Future directions for the Bulletin

The Bulletin's new website and design have been informed by surveys of the readership, current scientific practice and environmental sustainability.

D. Lynne Madden, Megan E. Black, Carlie-Jane Naylor, Richard Hecker

2 Strengthening learning opportunities to promote the capacity of the public health workforce

[Editorial] A skilled workforce is a major strategic resource for any industry and is dependent upon effective and accessible learning opportunities.

D. Lynne Madden

4 Problem-based learning in public health workforce training: a discussion of education principles and evidence Despite the challenges, problem-based learning has the potential to offer substantial educational gains in a field that is largely unexplored.

Lyndal J.Trevena

9 Using problem-based learning in public health service based training

This approach could play an important role in workforce development - its value is linked to experiential learning where knowledge, insight and understanding facilitate change in individual practice.

Gaynor S. Heading, Jeffrey D. Fuller, David M. Lyle,

D. Lynne Madden
13 Use of communication technologies by the public health workforce in New South Wales

Factors that foster use include ease of access to facilities and assistance in organising the technique; barriers include cost and the perception of difficulty.

Carlie-Jane Naylor, D. Lynne Madden, Deborah J. Oong

17 Influencing population health performance: Introduction of standards for area health services in New South Wales

Pilot evaluation revealed that with respect to the performance requirements of Greater Western Area Health Service, the standards were principally confined to the work of specialist population health staff.

Jeannine Liddle, David Lyle, Margaret Lesjak, Andrew Milat, Emma Webster, Thérèse Jones

22 Health surveillance among Australian health workers assisting tsunami victims in Aceh, Indonesia

Information, preventive measures and the provision of prepackaged food and water appears to be important in avoiding illness.

Jeremy M. McAnulty, Michael Flynn

Factsheet

25 Cryptosporidiosis

\section{Bug Breakfast in the Bulletin}

26 Refugee health

Katina Kardamanidis, Mitchell M. Smith, Sanjyot Vagholkar

Communicable Diseases Report, New South Wales

28 November and December 2006

\section{NSW PUBLIC HEALTH BULLETIN}

The NSW Public Health Bulletin is a peer-reviewed journal produced by the NSW Department of Health and indexed in Medline. It has a NSW focus, however, it aims to support the practice of public health more broadly.

\section{Editor}

Dr Lynne Madden

BSc(Med)Hons1, MBBS, MPH, MSc, FFPH, FAFPHM

\section{Assistant Editor}

Ms Megan Black

BSc, MPH, GradDipAppEpi

\section{Editorial correspondence}

Please address all correspondence and submissions to:

The Editor, NSW Public Health Bulletin Locked Mail Bag 961

North Sydney NSW 2059 Australia
Email:phbulletin@doh.health.nsw.gov.au Telephone:+61 294245876

Fax:+61293919232

\section{Submission of articles}

The Bulletin accepts proffered and commissioned articles along with short reports, on all aspects of public health. Articles should be 1500-2000 words, not including tables and figures, and should include an abstract of up to 100 words. Articles should follow the journal style and layout as closely as possible, as described in the Instructions to Authors. Articles should be emailed in a Word for Windows format to:phbulletin@doh.health.nsw.gov.au, and should be accompanied by a covering letter signed by all authors and a License to Publish. The Instructions to Authors, License to
Publish and other useful information can be downloaded from the Bulletin website.

\section{Distribution}

The Bulletin is freely available from the Bulletin website. Copies of the current issue and back issues can be downloaded in both PDF and HTML formats. If you would like to be notified when new issues of the Bulletin are available online, subscribe to the early alert email system at the Bulletin website. The early alert email contains the contents of each new issue along with electronic links to the articles. To receive a printed copy of the Bulletin, subscribe online at the Bulletin website, or contact your local public health unit or the editorial office.

Website: www.publish.csiro.au/journals/phb Copyright @ 2007 NSW Department of Health 